\title{
Glial Scar Borders Are Formed by Newly Proliferated, Elongated Astrocytes That Interact to Corral Inflammatory and Fibrotic Cells via STAT3-Dependent Mechanisms after Spinal Cord Injury
}

\author{
Ina B. Wanner, ${ }^{1}$ Mark A. Anderson, ${ }^{2}$ Bingbing Song, ${ }^{2}$ Jaclynn Levine, ${ }^{1}$ Ana Fernandez, ${ }^{1}$ Zachary Gray-Thompson, ${ }^{1}$ \\ Yan Ao, ${ }^{2}$ and Michael V. Sofroniew ${ }^{2}$ \\ ${ }^{1}$ Semel Institute for Neuroscience and Human Behavior and ${ }^{2}$ Department of Neurobiology, David Geffen School of Medicine, University of California Los \\ Angeles, Los Angeles, California, 90095-1763
}

\begin{abstract}
Astroglial scars surround damaged tissue after trauma, stroke, infection, or autoimmune inflammation in the CNS. They are essential for wound repair, but also interfere with axonal regrowth. A better understanding of the cellular mechanisms, regulation, and functions of astroglial scar formation is fundamental to developing safe interventions for many CNS disorders. We used wild-type and transgenic mice to quantify and dissect these parameters. Adjacent to crush spinal cord injury (SCI), reactive astrocytes exhibited heterogeneous phenotypes as regards proliferation, morphology, and chemistry, which all varied with distance from lesions. Mature scar borders at $14 \mathrm{~d}$ after SCI consisted primarily of newly proliferated astroglia with elongated cell processes that surrounded large and small clusters of inflammatory, fibrotic, and other cells. During scar formation from 5 to $14 \mathrm{~d}$ after SCI, cell processes deriving from different astroglia associated into overlapping bundles that quantifiably reoriented and organized into dense mesh-like arrangements. Selective deletion of STAT3 from astroglia quantifiably disrupted the organization of elongated astroglia into scar borders, and caused a failure of astroglia to surround inflammatory cells, resulting in increased spread of these cells and neuronal loss. In cocultures, wild-type astroglia spontaneously corralled inflammatory or fibromeningeal cells into segregated clusters, whereas STAT3-deficient astroglia failed to do so. These findings demonstrate heterogeneity of reactive astroglia and show that scar borders are formed by newly proliferated, elongated astroglia, which organize via STAT3-dependent mechanisms to corral inflammatory and fibrotic cells into discrete areas separated from adjacent tissue that contains viable neurons.
\end{abstract}

\section{Introduction}

After traumatic injury, stroke, infection, autoimmune inflammation, or other severe insults in the CNS, areas of focal tissue damage become filled with inflammatory, fibrotic, and other cells that derive from the perivascular cells, endothelia, bone marrow, and meninges; these tissue lesions become surrounded by astroglial scars that separate necrotic from healthy tissue (Sofroniew and Vinters, 2010; Kawano et al., 2012). Although glial scar formation has been recognized for over 120 years and its negative effects of

Received May 17, 2013; revised June 23, 2013; accepted June 26, 2013.

Author contributions: I.W. and M.V.S. designed research; I.B.W., M.A.A., B.S., J.L., A.F., Z.G.-T., Y.A., and M.V.S. performed research; I.B.W., M.A.A., B.S., J.L., Y.A., and M.V.S. analyzed data; I.B.W. and M.V.S. wrote the paper.

This work was supported by National Institutes of Health Grant NS057624 (M.V.S.), The Neilsen Foundation (I.B.W.), The Dr. Miriam and Sheldon G. Adelson Medical Foundation (M.V.S.), The Roman Reed Spinal Cord Injury Fund of California (M.V.S.), and Wings for Life (M.V.S.). We thank Dr. J. Gornbein for assistance with statistics, R. Korsak for technical assistance, and J. Maldonado for assistance with image analysis.

The authors have no financial conflicts or interests.

Correspondence should be addressed to either Michael V. Sofroniew, Department of Neurobiology, David Geffen School of Medicine at UCLA, Los Angeles, CA 90095-1763, E-mail: sofroniew@mednet.ucla.edu; or Ina B. Wanner, Semel Institute for Neuroscience and Human Behavior, UCLA, Los Angeles, CA 90095, E-mail: iwanner@mednet.ucla.edu.

DOI:10.1523/JNEUROSCI.2121-13.2013

Copyright $(2013$ the authors $\quad 0270-6474 / 13 / 3312870-17 \$ 15.00 / 0$ inhibiting axon regrowth have been described and studied in considerable descriptive and mechanistic detail since that time (Ramon y Cajal, 1928; Silver and Miller, 2004), fundamental aspects of the cellular mechanisms, molecular regulation, and adaptive functions of astroglial contributions to scar formation remain poorly understood (Sofroniew, 2005, 2009). A better understanding of such events will be essential for developing therapeutic strategies that can safely facilitate axon regrowth past astroglial scars without disrupting their essential functions in tissue repair and neuroprotection (Bush et al., 1999; Faulkner et al., 2004).

In this study, we used in vivo and in vitro experimental models and transgenic mice to quantify and dissect specific aspects of the cellular dynamics and interactions during astroglial scar formation. After spinal cord injury (SCI), as in other CNS regions, tissue lesions consist of central areas of inflammatory, fibrotic, and other cells and a surrounding astroglial scar (Fawcett and Asher, 1999; Silver and Miller, 2004; Klapka and Muller, 2006; Sofroniew and Vinters, 2010; Kawano et al., 2012). Surprisingly little is known regarding the cellular interactions and signaling mechanisms whereby astroglia interact with each other to form scar borders or to surround other cells in the lesion core. Here, we 
investigated (1) phenotypic characteristics of reactive and scarforming astroglia, (2) cellular interactions among scar-forming astroglia during scar formation, and (3) cellular interactions among scar-forming astroglia and inflammatory and fibrotic cells after SCI or in vitro. To do so, we used different transgenic mouse models that (1) targeted the expression of marker proteins to astroglial cell bodies and processes thereby allowing their reliable identification and quantification (Bush et al., 1999; Faulkner et al., 2004; Zong et al., 2005) or (2) mediated the deletion of signal transducer and activator of transcription 3 (STAT3) selectively from astroglia to create a loss-of-function model that reliably disrupts astroglial scar formation after SCI (Herrmann et al., 2008). In vitro, we used primary cell cultures of confluent astroglia (Wanner et al., 2008; Wanner, 2012) and prepared cocultures by adding meningeal fibroblasts or macrophages (Niclou et al., 2003; Wanner et al., 2008) to assess spontaneous cellular interactions between astroglia and certain cell types in the lesion core.

Our findings show that phenotypic and proliferative changes among reactive astroglia are heterogeneous in a manner that varies with respect to their distance from SCI lesions. We found that scar borders are formed primarily by newly proliferated, elongated astroglia that organize via STAT3-dependent mechanisms to surround and corral inflammatory and fibrotic cells into discrete areas that are separated from adjacent tissue containing viable neurons.

\section{Materials and Methods}

Animals. All nontransgenic, transgenic, and control mice used in this study were derived from in-house breeding colonies backcrossed onto C57BL/6 backgrounds. Various lines of previously characterized transgenic mice were used. (1) mGFAP-TK transgenic mice were obtained by mating heterozygous females of mGFAP-TK line 7.1 with wild-type C57BL/6 males (Bush et al., 1998, 1999). mGFAP-TK mice were used for quantification of total numbers of astroglia and of double labeling of astroglia with bromodeoxyuridine (BrdU) because the TK provides robust labeling of astroglial cell bodies (Bush et al., 1998, 1999). In this regard it is noteworthy that mGFAP-TK mice develop normally and in the absence of treatment with ganciclovir exhibit no detectable detrimental effects of transgene expression such that brain structure and histology, including the appearance of astrocytes, are indistinguishable from nontransgenic littermates (Bush et al., 1998, 1999; Faulkner et al., 2004; Myer et al., 2006). (2) MADM transgenic reporter mice were kindly provided by Dr. Hui Zong (Zong et al., 2005; Hippenmeyer et al., 2010) and were crossed with the mGFAP-Cre mice line 73.12 (Garcia et al., 2004), which we have previously used and extensively characterized for targeting Cremediated recombination to astroglia in the context of SCI (Herrmann et al., 2008). The resulting mGFAP-Cre-MADM mice were used for sparse labeling of reactive and scar-forming astrocytes after SCI. (3) STAT3loxP mice having loxP sites flanking exon 22 of the STAT3 gene, which encodes a tyrosine residue (tyr705) essential for STAT3 activation as described previously (Takeda et al., 1998), were crossed with mGFAP-Cre mice line 73.12. We have previously used and extensively characterized the resulting mGFAP-STAT3-CKO mice in the context of SCI (Herrmann et al., 2008). Control mice of various genotypes were used including mice that (1) carried no transgene (i.e., nontransgenic or "wild-type" mice), (2) were only heterozygous for mGFAP-Cre, or (3) were only heterozygous or homozygous for loxP and carry no mGFAP-Cre.

All mice were housed in a $12 \mathrm{~h}$ light/dark cycle in a specific pathogenfree facility with controlled temperature and humidity and were allowed free access to food and water. All experiments were conducted according to protocols approved by the Animal Research Committee of the Office for Protection of Research Subjects at University of California Los Angeles. Mice were genotyped by PCR and where possible were confirmed by immunohistochemistry.

Surgical procedures. All surgical procedures were performed under general anesthesia with isoflurane in oxygen-enriched air using an oper- ating microscope (Zeiss), and rodent stereotaxic apparatus (David Kopf). Laminectomy of a single vertebra was performed and moderately severe crush SCIs were made at the level of L1/L2 using No. 5 Dumont forceps (Fine Science Tools) ground down to a tip width of $0.5 \mathrm{~mm}$ and modified with a $0.25 \mathrm{~mm}$ spacer to compress the cord laterally from both sides for $5 \mathrm{~s}$ as described previously (Faulkner et al., 2004; Herrmann et al., 2008). Animals were randomly assigned numbers and evaluated blind to genotype and experimental condition.

BrdU treatments. BrdU (Sigma), was administered by intraperitoneal injections at $100 \mathrm{mg} / \mathrm{kg}$ dissolved in saline plus $0.007 \mathrm{~N} \mathrm{NaOH}$. Each animal was given a single daily injection of this dose days 2 through 7 after SCI.

General histological and immunohistochemical procedures. After terminal anesthesia by barbiturate overdose, mice were perfused transcardially with buffered $4 \%$ paraformaldehyde. Spinal cords were removed, postfixed for a further $2 \mathrm{~h}$, and cryoprotected in buffered $30 \%$ sucrose overnight. Frozen sections ( $40 \mu \mathrm{m}$ transverse or $30 \mu \mathrm{m}$ horizontal) were prepared using a cryostat microtome (Leica) and processed for various kinds of histological evaluation. Staining with cresyl violet was conducted according to standard procedures. Details of bright-field and fluorescent immunohistochemistry and primary antibodies are described in separate sections below. Stained sections were examined and photographed using bright-field and fluorescence microscopy and scanning confocal laser microscopy (Zeiss).

Bright-field immunohistochemistry. Endogenous peroxidase was quenched using $1 \% \mathrm{H}_{2} \mathrm{O}_{2}$ in $100 \%$ methanol, sections were permeabilized in $0.5 \%$ Triton $\mathrm{X}-100$ and incubated in blocking sera matched to the species of secondary antibodies being used. Enzyme-linked immunohistochemistry was performed using two different substrates. After biotinylated secondary antibodies (Vector Laboratories) and biotin-avidin-peroxidase complex (Vector Laboratories), the developing substrates used were either diaminobenzidine (DAB; Vector Laboratories) (Faulkner et al., 2004; Herrmann et al., 2008) or a glucose oxidase-catalyzed nickel-enhanced procedure (Shu et al., 1988). Briefly, sections were incubated in a slowreacting glucose oxidase-catalyzed nickel-enhanced DAB for 5-10 min based on visual control.

Fluorescence immunohistochemistry. To block tissue autofluorescence sections were equilibrated in distilled water and incubated in Sudan black solution ( $0.5 \%$ in $70 \%$ ethanol solution) for $5 \mathrm{~min}$. Sections were permeabilized in $0.5 \%$ Triton X-100 and incubated in blocking sera matched to the species of second antibodies being used. Fluorescence immunohistochemistry was performed using secondary antibodies conjugated to Alexa 488 (green), Alexa 568 (red), or Alexa 350 (blue) (Invitrogen) or to Cy3 or Cy5 (Vector Laboratories and Millipore Bioscience Research Reagents). The nuclear stains, 4',6-diamidino-2-phenylindole dihydrochloride (DAPI; $2 \mathrm{ng} / \mathrm{ml}$; Invitrogen), or $10 \mu \mathrm{g} / \mathrm{ml}$ bisbenzimide in $\mathrm{H}_{2} \mathrm{O}$ (Hoechst; Sigma), were used as general cytological stains in fluorescent0stained sections. Sections were coverslipped using ProLong Gold antifade reagent (Invitrogen).

Primary antibodies for immunological staining. Primary antibodies were as follows: rabbit anti-glial fibrillary acid protein (GFAP; 1:2000 or 1:20,000; Dako), rat anti-GFAP (1:1000 or 1:5000; Zymed Laboratories), rabbit anti-aquaporin4 (1:10,000; Sigma), mouse anti-NeuN (1:400 or 1:4000; Millipore Bioscience Research Reagents), rat anti-mouse CD45 (1:100 or 1:2000; BD PharMingen), rabbit anti-herpes simplex virus thymidine kinase (HSV-TK; 1:20,000; Bush et al., 1999), sheep anti-BrdU (1:6000; Maine Biotechnology Services), rabbit anti-Ki67 (1:200; Vector Laboratories), goat anti-SOX2 (Y-17 1:200; Santa Cruz Biotechnology), goat anti-Nestin (1:300; R\&D Systems), rabbit anti-brain lipid binding protein (Blbp; 1:400; Millipore), mouse anti-RC2 (1:50; DSHB), mouse anti-LeX/CD15 (1:100; BD PharMingen), rat anti-CD133 (1:100; Millipore), rabbit anti-glutamine synthase (GS; 1:200; Sigma), rabbit antifibronectin (1:1000, Dako; 1:250, Abcam), and mouse anti-fibronectin (1:200; BD Transduction Labs). Different dilutions indicate use for fluorescence staining (higher concentration) or bright-field staining with DAB (lower concentration).

Morphometric analyses, image reconstructions, and statistical evaluations. Cell counts were determined using stereological image analysis software (StereoInvestigator or Neurolucida; MicroBrightField) operat- 
ing a computer-driven microscope regulated in the $x$-, $y$-, and $z$-axes (Zeiss) in a manner described in detail previously (Faulkner et al., 2004; Herrmann et al., 2008). For cell density measurements zones across spinal cord sections were traced in at least $n=4$ mice per group using a computer-driven stage, and cell numbers were counted and the volume of the counted tissue calculated on the basis of $x$-, $y$-, and $z$-axis measures by the image analysis software. Statistical evaluations were performed by ANOVA with post hoc, independent pairwise analysis as per NewmanKeuls or Bonferroni (Prism; GraphPad).

Morphometric analyses and reconstruction of bundles formed by cell processes of elongated astroglia were performed using Neurolucida in $n=11$ control and $n=11$ STAT3 CKO mice at 5, 7, 9, 12, 14, and $21 \mathrm{~d}$ after SCI. Bundle traces of six sections per spinal cord were overlaid to generate reconstruction drawings. Bundle number and thickness were automatically recorded during bundle tracing. Bundle angle was recorded relative to the closed lesion edge. Statistical analyses compared means of (log) bundle number, thickness, and angle using a repeated measure ANOVA (mixed ANOVA) model (SAS 9.3, Procedure MIXED) corresponding to a $2 \times 6$ genotype $\times$ time postinjury design. Examination of the pooled residual errors (data subtracted by means) in histogram and quantile normal probability plots confirmed that means of thickness, orientation, and log bundle number followed the Gaussian distribution (data not shown). Data were fitted to trends using constant, linear, or other models or a fit was rejected based on goodness of fit (using $\chi^{2} / \mathrm{df}$ with $\chi^{2}: \chi^{2}$; df, deviance of fit) and equality of means $(F$, overall $p$ value). The Fisher least significant difference (LSD) criterion was used to control for type I error for pairwise mean comparisons under the model. Since the distribution of log bundle number, not bundle number, followed the Gaussian, geometric means are reported for bundle number on the original scale.

Astrocyte monocultures. Astrocytes were prepared from neonatal mouse cortices as described previously (Wanner, 2012). Each animal was processed separately and tails were collected for genotyping. Briefly, cortical homogenates were dissociated and filtered to remove capillaries. Cortical cells were expanded for 1 week and confluent cells were shaken for astrocyte enrichment. Cell suspensions of 30-35,000 astrocytes in 0.5 $\mathrm{ml}$ medium were seeded onto $180 \mathrm{~mm}^{2}$ well glass chamber slides (BD Transduction Laboratories) coated with poly-L-lysine and grown to confluence. Postmitotic astrocytes were differentiated by stepwise switch to medium with 10\% adult equine serum (Atlanta Biologicals; heat inactivated) followed by stepwise serum withdrawal (Wanner, 2012).

Isolation of meningeal fibroblasts and macrophages for cocultures. Meningeal cell cultures were prepared based on protocols for rat (Niclou et al., 2003; Wanner et al., 2008) with the following modifications. Cortical meninges from neonatal wild-type mice were collected and digested with $0.2 \%$ trypsin, $0.25 \%$ collagenase, and $40 \mu \mathrm{g} / \mathrm{ml}$ DNase I in HBSS for $30 \mathrm{~min}$ at $37^{\circ} \mathrm{C}$. Cells were dissociated by slow trituration with a P1000 tip in the presence of DNase I. Washed cells were collected by 5 min centrifugation at 400 $g$. The cell suspension from 10 cortical meninges was grown to confluence in DMEM/F12, 10\% fetal bovine serum (FBS) in a T75 flask within 4-5 d and consisted of enriched meningeal fibroblasts used for astrocyte-fibroblast cocultures. Meningeal cell cultures kept an additional 7-10 d without medium change resulted in substantial increase of meningeal macrophages, which were then the predominant cell type. These cells were used for astrocytemacrophage cocultures. Cocultures were prepared by adding a suspension of 30-35,000 meningeal cells highly enriched for either fibroblasts or macrophages to an area of $180 \mathrm{~mm}^{2}$ confluent astrocytes prepared from either control or STAT3-CKO mice, and cocultures were incubated in DMEM/ F12, 10\% FBS for 2-3 d. Cocultures were fixed for $30 \mathrm{~min}$ in ice-cold, freshly depolymerized $4 \%$ paraformaldehyde.

Cell culture immunocytochemistry. Cultures were permeabilized in $0.3 \%$ Triton, rinsed, and incubated in blocking sera. Primary antibodies were incubated in blocking solution overnight and developed with fluorescent probes as described above. Biotinylated Tomato lectin (1:50; Sigma) binding to macrophage cells was detected using Streptavidin Cy3 (1:200; Jackson ImmunoResearch). Nuclei of rinsed cultures were stained using Hoechst dye as above.

Cell culture image analyses and quantitative evaluations. Images were acquired using $10 \times$ and $20 \times$ objectives on an inverted microscope
(Olympus IX70) equipped with a black and white CCD camera (AxioCam, Zeiss) and sequential channel image capture software (AxioVision 4.6). Using these images, the following analyses were performed using the same approach to determine (1) area coverage, (2) cluster number, and (3) cell density of added macrophages or fibroblasts. In addition, $\left(2^{\star}\right)$ fibroblast cluster sizes were binned because they varied, whereas this was not pertinent for macrophages. (1) AxioVision outline spline tool was used to trace CD45-positive areas (in cocultures of three animals per genotype) or fibronectin-positive areas (six Control and four STAT3-CKO animals). Then, the percentage coverage of each image $\left(667,518 \mu \mathrm{m}^{2}\right)$ was calculated. (2) Counted were clusters of CD45positive cells (three animals per genotype) or fibronectin-positive cells (five Control and six STAT3-CKO animals) over $0.8-3.2 \mathrm{~cm}^{2}$ and data were normalized to $1 \mathrm{~cm}^{2} .\left(2^{*}\right)$ : In these fibronectin-stained cocultures fibroblast clusters were also binned by size, defining clusters of 2-11 cells as "small," those with 12-49 cells "medium," and clusters with 50 and more cells as "large." (3) Cell density within a cluster was determined by counting CD45-positive cells (three animals per genotype) or fibronectin-positive cells (four animals per genotype) using an 11,229 $\mu \mathrm{m}^{2}$ rectangle placed within 20-25 clusters per coculture type and normalizing cell numbers to $100 \mu \mathrm{m}^{2}$.

\section{Results}

\section{Heterogeneity of reactive astroglia adjacent to SCI: mature scar-forming astroglia exhibit distinctive elongated morphologies with extensively overlapping cell processes}

Our first objective was to characterize the phenotype of reactive astroglia that form the scar border that immediately interfaces with, and surrounds, damaged and inflamed tissue lesions after SCI. Previous studies have suggested heterogeneity among reactive astroglia such that astroglia along scar borders differ in extent of overlap of cellular processes and in degree of cell proliferation from other reactive astroglia that are not immediately adjacent to tissue lesions (for review, see Sofroniew, 2009); however, such differences have not been systematically defined or quantified. To do so, we used different lines of transgenic mice to define the morphology and quantify the degree of proliferation of reactive astroglia in different locations with respect to the lesion core after SCI.

We began by identifying an early time point, for use in subsequent analyses, at which astroglial scar formation could reliably be regarded as essentially completed in our model of crush SCI. Using immunohistochemistry for GFAP in wild-type mice, we found that the appearance of the astroglial scar border and adjacent regions at $14 \mathrm{~d}$ was not fundamentally different from that at $28 \mathrm{~d}$ (Fig. $1 A-G$ ) or 8 weeks (data not shown). In a manner consistent with many previous studies (Fawcett and Asher, 1999; Silver and Miller, 2004; Klapka and Muller, 2006; Sofroniew and Vinters, 2010; Kawano et al., 2012), we found that astroglia surrounded central lesion areas that contained few, and often no, astroglia (Fig. $1 A-D$ ). Such central lesion areas have been defined extensively by others and contains inflammatory, fibrotic, and various other types of cells (Fawcett and Asher, 1999; Silver and Miller, 2004; Klapka and Muller, 2006; Kawano et al., 2012). We refer to central lesion areas surrounded by astroglial scars as lesion cores. Mature astroglial scar borders that immediately surrounded tissue lesions with lesion cores were easily identified (Fig. $1 A-D$ ). At both 14 and $28 \mathrm{~d}$ after SCI, the mature astroglial scar border found in the first few hundred micrometers immediately abutting lesion cores consisted of many long GFAP-positive astroglial cell processes that were intertwined and overlapped in a dense meshwork (Fig. 1A-D). We therefore used $14 \mathrm{~d}$ after SCI as the time point for most of our subsequent evaluations of mature astroglial scars. During these initial evaluations, we also noted, at both 14 and $28 \mathrm{~d}$ after SCI, that in tissue more distant from the 

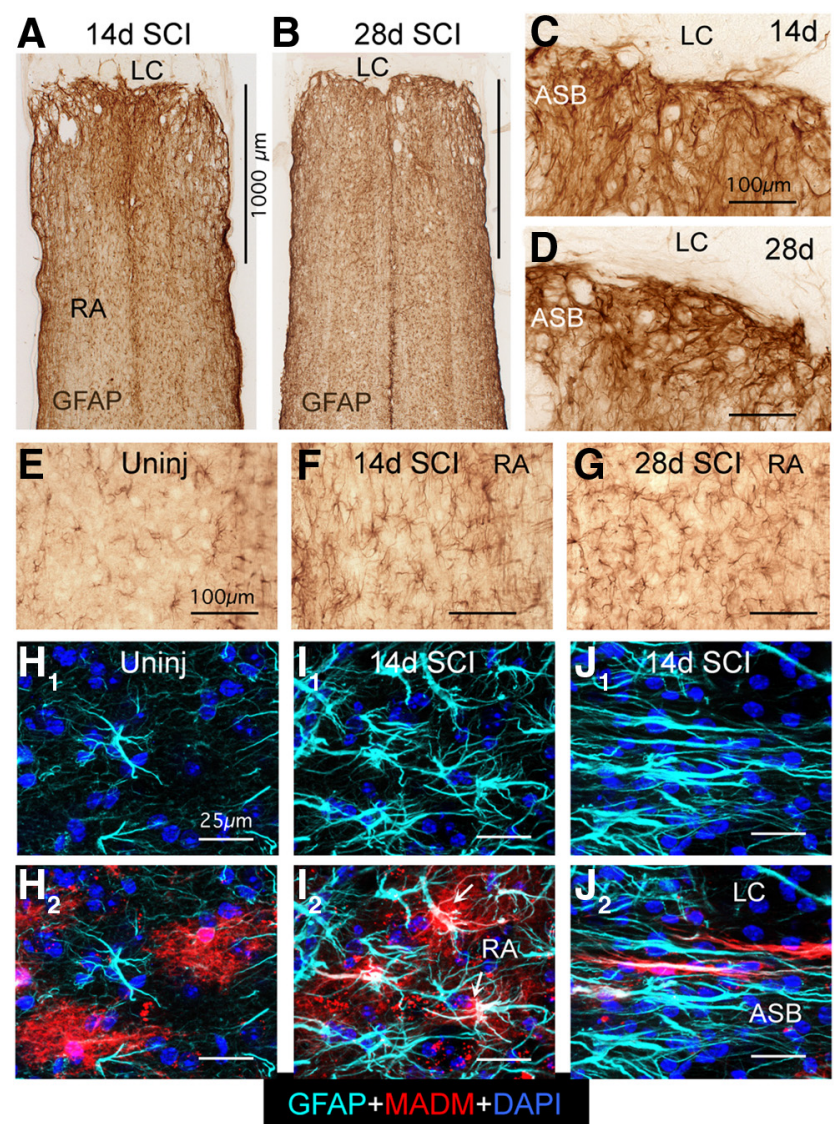

Figure 1. Mature scar borders adjacent to $S C l$ lesions consist of reactive astroglia (RA) that have elongated overlapping morphologies. $\boldsymbol{A}-\mathbf{G}$, Bright-field immunostaining of GFAP in horizontal sections of thoracic spinal cord at $14(\boldsymbol{A}, \boldsymbol{C}, \boldsymbol{F})$ and $28 \mathrm{~d}(\boldsymbol{B}, \boldsymbol{D}, \boldsymbol{G})$ after $S \mathrm{Cl}$ and in uninjured spinal cord $(\boldsymbol{E})$. Note that GFAP-positive cell processes overlap extensively in the astroglial scar border (ASB) immediately adjacent to the lesion core and lesion core (LC), in contrast with the nonoverlapping cell processes and stellate appearance of hypertrophied RA at $1 \mathrm{~mm}$ or more distant from the SCl. $\boldsymbol{H}-\boldsymbol{J}$, Multicolor fluorescence confocal imaging of MADM reporter and GFAP immunostaining in uninjured spinal cord $(\boldsymbol{H})$ and at $14 \mathrm{~d}(\boldsymbol{I}, \boldsymbol{J})$ after $\mathrm{SCl} . \boldsymbol{H}_{\boldsymbol{1}}-\boldsymbol{J}_{1}$, Single-channel imaging of GFAP immunoreactivity, which visualizes only the astroglial cytoskeleton in light blue. $\boldsymbol{H}_{2}-J_{2}$, Dual-channel imaging of both GFAP immunoreactivity in light blue and MADM reporter in red, which visualizes the entire astroglial cytoplasm. Note that the bushy nature of protoplasmic astroglia and individual astrocyte domains revealed by the MADM reporter in uninjured astroglia $(\boldsymbol{H})$ are more or less preserved in hypertrophied reactive stellate astroglia distant from the lesion core (arrows, I), whereas the RA that form the scar border immediately abutting the LC have elongated shapes as revealed also by the MADM cytoplasmic staining, and that the processes of different astroglia overlap extensively and are in close proximity to one another $(\boldsymbol{J})$. Scale bars: $\boldsymbol{A}$ (for $\boldsymbol{A}, \boldsymbol{B}$ ), $1000 \mu \mathrm{m} ; \boldsymbol{C}-\mathbf{G}, 100 \mu \mathrm{m}$; in $\boldsymbol{H}-\mathbf{I}, 25 \mu \mathrm{m}$.

lesion core $(>1 \mathrm{~mm})$, the reactive astroglia exhibited a stellate appearance essentially similar to that in uninjured tissue but with evidence of increased expression of GFAP and cellular hypertrophy (Fig. 1 A, B,E-G). Nevertheless, it was clear that bright-field staining for GFAP alone was not a sufficient marker for accurate evaluation of differences in astrocyte morphology in different regions in the vicinity of SCI lesions. We therefore used other techniques to characterize these cells.

To define more precisely the different morphologies of reactive astroglia located either in the SCI scar border or distant to lesion cores, we used the mosaic analysis with double markers (MADM) transgenic targeting method to achieve sparse labeling of individual astrocytes labeled in their entirety with cytoplasmically expressed reporter protein. MADM uses Cre-loxPmediated interchromosomal recombination to achieve a sparse labeling of cells with cytoplasmic reporter proteins (Zong et al., 2005; Hippenmeyer et al., 2010), where the specificity of cell targeting is achieved via transgenically targeted Cre-recombinase. For targeting, we used our previously well characterized mGFAPCre line that targets $>97 \%$ of GFAP-positive astrocytes after SCI and no other cell types (Herrmann et al., 2008). In offspring from MADM crosses with our mGFAP-Cre mice, we found that $\sim 10$ $20 \%$ of astroglia were routinely labeled with MADM reporters and that positive cells exhibited reporter labeling throughout the cytoplasm enabling visualization of the entire cell and its processes (Fig. $1 H-J)$.

Using the MADM method in combination with GFAP immunohistochemistry, we found that in uninjured spinal cord, protoplasmic astroglia exhibited highly variable levels of GFAP expression, ranging from almost undetectable to moderate, and that MADM labeling of scattered cells revealed a bushy morphology of highly branching fine cellular processes with essentially nonoverlapping individual cellular domains (Fig. $1 H_{1}, H_{2}$ ) similar to the morphology and domains described in forebrain using cell-filing or membrane-labeling technologies (Bushong et al., 2002; Shigetomi et al., 2013). After crush SCI, the reactive astroglia in tissue more distant from the large central lesion core $(>1$ $\mathrm{mm}$ ) exhibited a clear and pronounced upregulation of GFAP such that all astroglia expressed high levels of GFAP and some somatic hypertrophy (Fig. $1 I_{1}$ ). Nevertheless, these reactive astroglia retained both their basically stellate appearance with GFAP and their basic bushy appearance with MADM labeling (Fig. $\left.1 I_{1}, I_{2}\right)$, in a manner similar to that described in forebrain using single cell filing technology (Wilhelmsson et al., 2006). In striking contrast, in the astroglial scar border immediately adjacent to the lesion core, MADM labeling combined with GFAP immunohistochemistry revealed that individual astroglia exhibited distinctive elongated morphologies with long cellular processes that overlapped extensively (Fig. $1 J_{1}, J_{2}$ ). MADM labeling further revealed that astroglia in the scar border did not have a bushy appearance or fine branches, and there were many cases in which elongated processes from different cells were in close apposition with one another over long stretches (Fig. $1 J_{2}$ ).

These findings provide clear evidence for the heterogeneity of reactive astroglia in the vicinity of SCI lesions. Astroglia in scar borders immediately adjacent to tissue lesions exhibited distinctive elongated morphologies with overlapping and interacting processes. With increasing distance form lesion borders, reactive astroglia transitioned in a clearly graded fashion to morphologies more similar to those seen in healthy tissue. In regions from 1 to $2 \mathrm{~mm}$ away from lesions, reactive astroglia upregulated GFAP and exhibited somatic hypertrophy, but nonetheless retained their basic bushy or stellate shapes with more or less well preserved individual domains of cellular processes, in a manner essentially similar to that exhibited by astroglia in uninjured tissue.

\section{Mature astroglial scar borders are comprised primarily of newly proliferated, elongated astroglia}

We next determined the contribution of cell proliferation to the formation of astroglial scar borders and reactive astrogliosis in adjacent regions after SCI. Previous studies using various methods have shown that there are newly proliferated reactive astroglia in areas near damaged tissue after CNS trauma (Norton et al., 1992; Amat et al., 1996; Bush et al., 1999; Faulkner et al., 2004; Zai and Wrathall, 2005). In addition, transgenically targeted ablation of proliferating reactive astroglia severely disrupts scar formation adjacent to CNS trauma (Bush et al., 1999; Faulkner et al., 2004). Nevertheless, a precise analysis of the numerical proportion or 
A
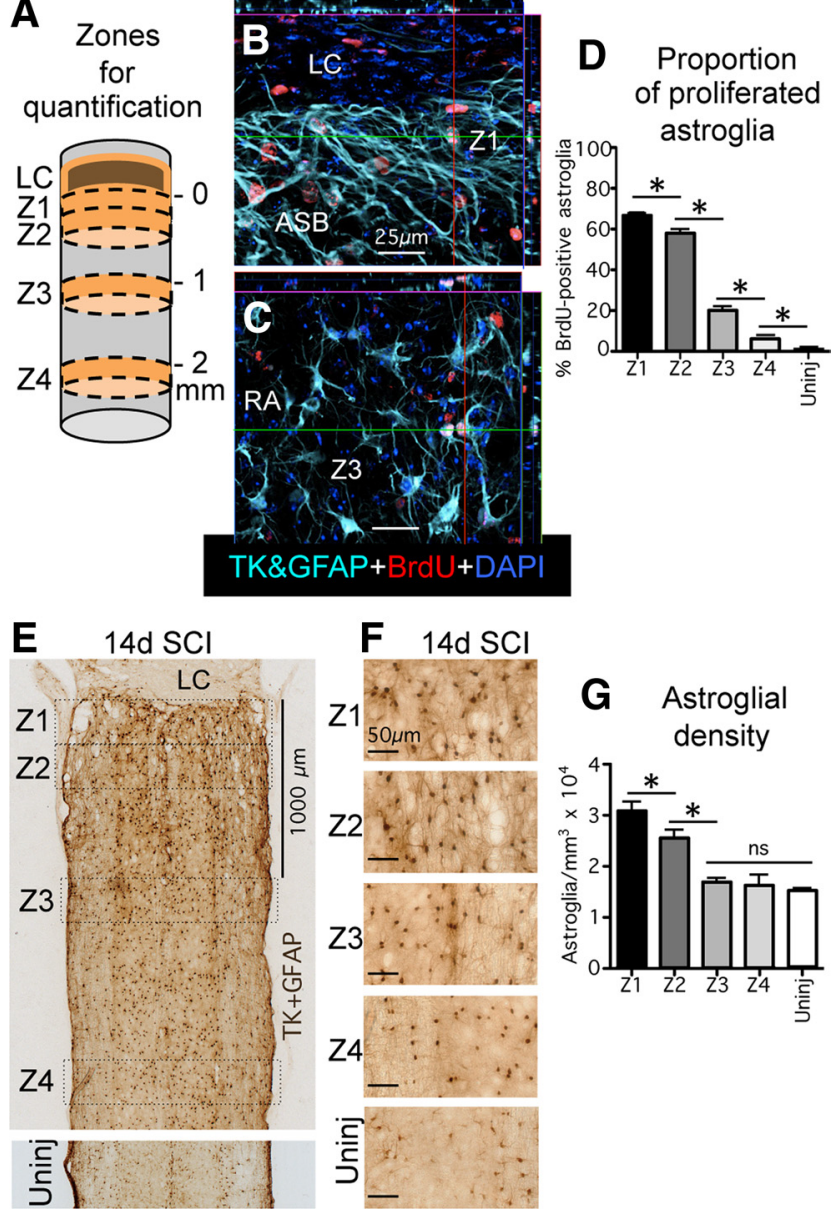

Figure 2. Mature scar borders consist of newly proliferated astroglia and have a higher density of astroglia than healthy tissue. $A$, Schematic drawing of spinal cord after $\mathrm{SCl}$ depicting the central core lesion with lesion core (LC) and four zones (Z1-Z4) of $250 \mu \mathrm{m}$ width used for various quantitative morphometric evaluations. The border where the astroglia scar abuts the $\mathrm{LC}$ was taken as zero and Z1 was measured from this point. Z2 was started immediately adjacent to $Z 1$. Z3 and Z4 were started at 1 and $2 \mathrm{~mm}$, respectively, from zero. $B, C$, Multicolor fluorescence immunostaining for TK + GFAP and BrdU in Z1 (B) and in Z3 ( () at $14 \mathrm{~d}$ after SCl. Note the high proportion of BrdU labeling of elongated astroglia in the astroglial scar border (ASB) in Z1 $(\boldsymbol{B})$ and that far fewer reactive astroglia (RA) are BrdU labeled in Z3 (C). D, Graph showing the proportion of BrdU-labeled, newly proliferated astroglia in Z1-Z4 after $\mathrm{SCl}$ and in uninjured tissue. $\boldsymbol{E}, \boldsymbol{F}$, Bright-field immunostaining of GFAP + TK showing survey $(\boldsymbol{E})$ and details $(\boldsymbol{F})$ of scar forming and RA cell bodies in Z1-Z4 after SCl and in uninjured tissue. G, Graph showing the density of astroglial cell bodies in Z1-Z4 after SCl and in uninjured tissue. $n=4$ per group. ${ }^{*} p<$ 0.05 (ANOVA with post hoc pairwise Bonferroni comparison). Scale bars: $B, C, 25 \mu \mathrm{m} ; \boldsymbol{E}, 1000$ $\mu \mathrm{m} ; \boldsymbol{F}, 50 \mu \mathrm{m}$.

topographical distribution of newly proliferated astroglia after CNS injury has been lacking. We therefore conducted quantitative evaluations of (1) the relative numerical contribution of newly proliferated astroglia and (2) the overall cellular density of astroglia, in precisely defined zones located at increasing distances adjacent to SCI lesions (Fig. $2 A-G$ ).

To quantify the relative proportion of newly proliferated astroglia, mice were administered a single injection of BrdU on each day from 2 to $7 \mathrm{~d}$ after SCI. BrdU is incorporated permanently into DNA and provides a permanent record of cells that were proliferating at the time BrdU was administered. Previous studies have shown that most, if not all, astroglial cell proliferation after CNS trauma occurs during the 2 to $7 \mathrm{~d}$ time frame after SCI in rodents (Norton et al., 1992; Amat et al., 1996; Bush et al., 1999; Faulkner et al., 2004; Zai and Wrathall, 2005). To increase the accuracy of detecting BrdU in astroglial cell bodies, we used mice that robustly express HSV-TK or TK from the transgene mGFAP-TK in cell bodies and nuclei, which we then detected as a reporter molecule for quantitative analysis of double labeling (Bush et al., 1998, 1999). This was done because GFAP staining is frequently absent from cell bodies, making it difficult to accurately colocalize GFAP with nuclear markers of cell division such as BrdU and Ki67, which in turn leads to many false negative observations and underestimates when quantifying double labeling. We have previously shown that in mGFAP-TK mice, immunohistochemistry for TK labels over 95\% of GFAP-positive cells and that $100 \%$ of TK-positive cells also express GFAP (Bush et al., 1998, 1999).

The proportion of BrdU-positive astroglia in mature astroglial scar borders and adjoining regions was determined at $14 \mathrm{~d}$ after crush SCI. For quantitative evaluations, we used a series of three evenly spaced, $30-\mu \mathrm{m}$-thick horizontal sections through the center of horizontally sectioned spinal cord, stained in multiple fluorescent colors for BrdU, GFAP + TK. and the nuclear marker DAPI (Fig. 2B,C). In each section, we delineated four zones at specific distances away from the easily identified edge of the astroglia scar border abutting the large central lesion on both the rostral and caudal sides (Fig. 2A,E). The zones were drawn across the entire diameter of each horizontal section and consisted of (Z1) $0-250 \mu \mathrm{m}$ immediately abutting the lesion core, (Z2) 250-500 $\mu \mathrm{m}$ away, (Z3) 1000-1250 $\mu \mathrm{m}$ away, and (Z4) 2000-2250 $\mu \mathrm{m}$ away (Fig. 2A,E). In uninjured mice, we also evaluated a $0-250 \mu \mathrm{m}$ zone across three horizontal sections at equivalent rostrocaudal levels of the spinal cord. Within these zones we quantified the ratio of newly proliferated, BrdU-labeled astroglia as a percentage of the total number of astroglia labeled with immunohistochemistry for TK + GFAP (Fig. $2 B-D$ ) by examining stacks of confocal images taken with a $\times 40$ objective viewed as 3D projections. At least 100 GFAP + TKpositive astroglial cells per zone per animal were evaluated for BrdU content.

In healthy, uninjured spinal cord, we found that the percentage of BrdU-labeled astroglia was $<1 \%$ of the total number of astroglia in both gray and white matter (Fig. 2D) in agreement with previous reports. After SCI, the percentage of BrdU-labeled astroglia was highest in Z1 in the $0-250 \mu \mathrm{m}$ immediately abutting the lesion core, where it was over $66 \%$ (Fig. 2D). In Z2, $250-500 \mu \mathrm{m}$ away from the lesion, the percentage of BrdUlabeled astroglia was also high at over $57 \%$, but was significantly lower by $9 \%$ relative to Z1 (Fig. 2D). In zone three, 1000-1250 $\mu \mathrm{m}$ from the lesion, the percentage of BrdU-labeled astroglia dropped markedly and significantly to $<20 \%$; in zone 4,2000 $2250 \mu \mathrm{m}$ from the lesion, the percentage dropped further to $<6 \%$, where it approached that in healthy tissue. In all zones, values in gray and white matter did not differ significantly (ANOVA), and values in the zones rostral or caudal to the lesion did not differ significantly (ANOVA), and so the data were pooled to obtain a single value for each zone. For interpreting these data, it deserves mention that (1) BrdU is rapidly cleared by the kidney and (2) BrdU labels cells during the S-phase of cell division, which is estimated to last $<12 \mathrm{~h}$ in astroglia. Thus, a single daily injection of $\mathrm{BrdU}$ will not label all cells that might divide during a $24 \mathrm{~h}$ period, and our observation that over $66 \%$ of astroglia were labeled with $\mathrm{BrdU}$ in the immediate border zone using our delivery paradigm can be regarded as an underestimate.

We next quantified the contribution of cell proliferation to the tissue density of astroglial cells in scar borders and adjacent regions after SCI (Fig. 2E-G). To do so, we conducted stereological 

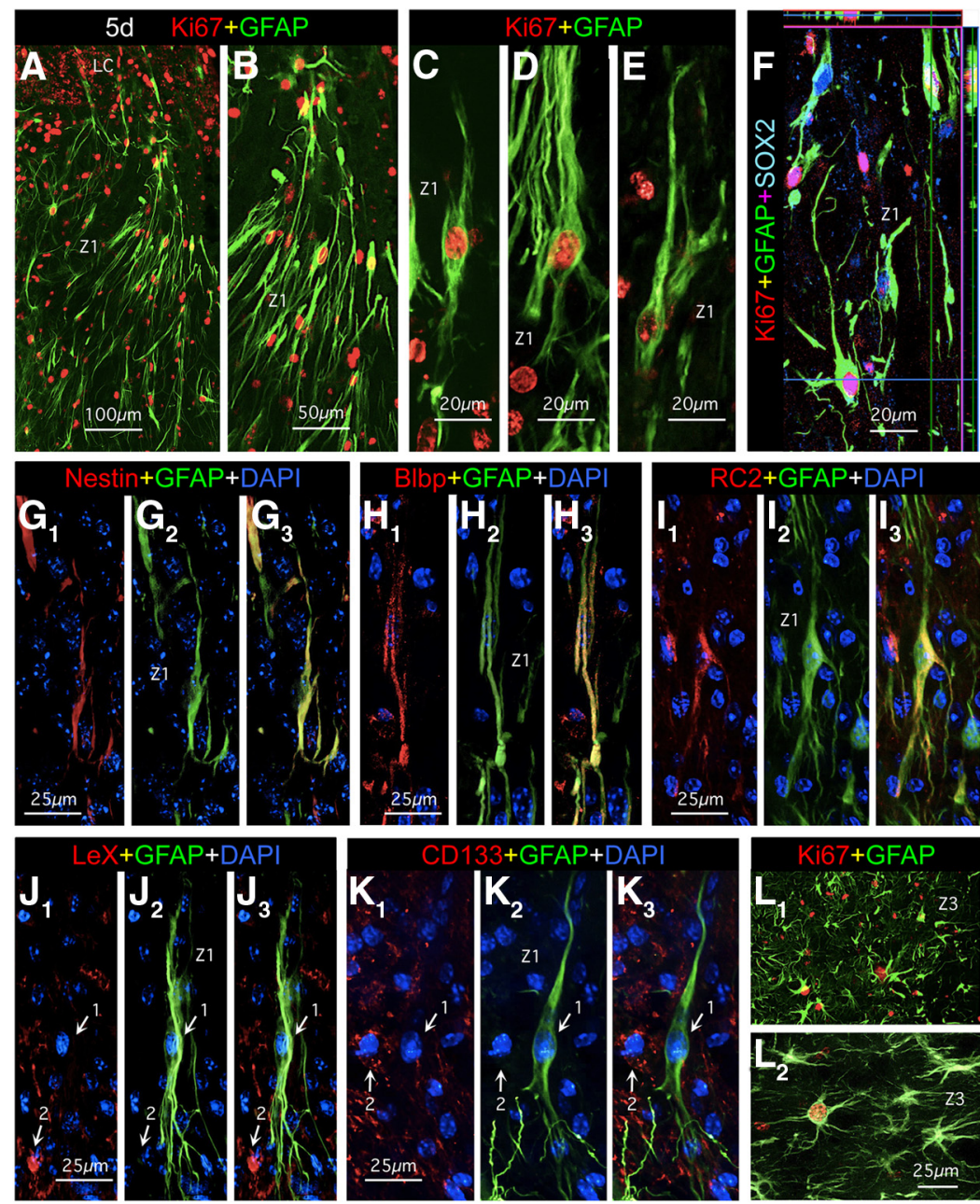

Figure 3. At $5 \mathrm{~d}$ after $\mathrm{SCl}$, the perimeters of tissue lesions in $\mathrm{Z1}$ contain many actively proliferating elongated astroglia that express some but not other progenitor markers. $A-L$, Multicolor fluorescence immunostaining for GFAP and various other markers in Z1 $(\boldsymbol{A}-\boldsymbol{K})$ and Z3 $(\boldsymbol{L})$ at 5 d after $\mathbf{S C l}$. $\boldsymbol{A}-\boldsymbol{I}$, Elongated GFAP-positive astroglia at the perimeters of lesions (Z1) at $5 \mathrm{~d}$ stain positively for the cell-cycle marker Ki67 $(\boldsymbol{A}-\boldsymbol{F})$ as well as for SOX2 $(\boldsymbol{F})$, nestin $(\boldsymbol{G})$, Blbp $(\boldsymbol{H})$, and RC2 $(\boldsymbol{I})$. $\boldsymbol{J}, \boldsymbol{K}$, Elongated GFAP-positive astroglia (arrows, 1) do not stain for LeX (CD15) (J) or CD133 (K) although other nearby cells do (arrows, 2). $\boldsymbol{L}$, In Z3 at $1 \mathrm{~mm}$ distance from the SCI lesion, GFAP-positive reactive astroglia have a more extensively branched stellate morphology and only a few of these cells are actively proliferating and express Ki67. Scale bars: $\boldsymbol{A}, \boldsymbol{L}, 100 \mu \mathrm{m} ; \boldsymbol{B}, 50 \mu \mathrm{m} ; \boldsymbol{C}-\boldsymbol{F}, 20, \mu \mathrm{m} ; \boldsymbol{G}-\boldsymbol{K}, 25 \mu \mathrm{m}$.

evaluations using StereoInvestigator (MicroBrightField) on a series of three evenly spaced, $30-\mu \mathrm{m}$-thick horizontal sections through the center of horizontally sectioned spinal cord, stained in bright field for GFAP + TK. In each section, the total number of positively stained astroglial cell bodies was counted in the same four zones at specific distances from the edge of the lesion, or in uninjured tissue (Fig. 2A,E). Quantitative stereology conducted in this manner estimated that in healthy, uninjured spinal cord, the density of GFAP + TK-positive astroglial cell bodies was $\sim 14,600$ cells $/ \mathrm{mm}^{3}$ in both gray and white matter (Fig. $2 G$ ). In all zones, in both uninjured tissue and after SCI, values in gray and white matter did not differ significantly (ANOVA), and values in the zones rostral or caudal to the lesion did not differ significantly (ANOVA), and so the data were pooled to obtain a single value for each zone. After SCI, the stereologically estimated density of astroglial cell bodies was highest in zone 1 in the $0-250 \mu \mathrm{m}$ immediately abutting the lesion, where it was just over 30,000 cells $/ \mathrm{mm}^{3}$ and approximately double that found in uninjured tissue (Fig. 2G). In Z2, 250-500 $\mu \mathrm{m}$ away from the lesion, the density was somewhat, but significantly, lower than in $\mathrm{Z1}$, at $\sim 27,500$ cells $/ \mathrm{mm}^{3}$, which was substantively and significantly higher than that in uninjured tissue (Fig. $2 G$ ). In contrast, in both Z3 (1000-1250 $\mu \mathrm{m}$ from the lesion), which was $\sim 16,200$ cells $/ \mathrm{mm}^{3}$, and Z4 (2000-2250 $\mu \mathrm{m}$ from the lesion), which was $\sim 15,500$ cells $/ \mathrm{mm}^{3}$, the densities of astroglial cell bodies were both substantially and significantly lower than those in $\mathrm{Z} 1$ and $\mathrm{Z} 2$ and did not differ significantly from that in uninjured tissue.

Together, these findings showed that after SCI, (1) mature astroglial scar borders that immediately interface with and surround, damaged and inflamed tissue, were comprised primarily of newly proliferated astroglia with elongated cell processes; (2) there was a gradient of astroglial proliferation that diminishes with distance from the SCI lesion; (3) the density of astroglial cell bodies in the scar border was nearly double that in uninjured tissue; and (4) accompanying the gradient of diminishing astroglial proliferation there was also a gradient of diminishing density of astroglial cells with distance from the SCI lesion, which gradually transitioned to a density similar to that seen in healthy tissue.

Proliferating astroglia adjacent to early SCI lesions have elongated, bipolar, or radial shapes and express certain markers associated with progenitor cells

Our next objective was to examine the phenotypes and locations of actively dividing astroglia during the proliferative period after SCI. To do so, we used immunohistochemistry for Ki67 as a marker of active proliferation, in combination with astroglia markers. Ki67 is a cell cycle protein that is expressed only by actively dividing cells (Gerdes et al., 1984) and for this reason, positive staining for $\mathrm{Ki} 67$ is a reliable indicator that a cell was actively dividing at the time of perfusion fixation. In agreement with previous studies (Norton et al., 1992; Amat et al., 1996; Bush et al., 1999; Faulkner et al., 2004; Zai and Wrathall, 2005), we found many actively proliferating Ki67-positive astroglia at 3 and $5 \mathrm{~d}$ after SCI, whereas there were far fewer at $7 \mathrm{~d}$ and essentially none at $14 \mathrm{~d}$. We focused our evaluations on $5 \mathrm{~d}$ after SCI, where we found that the majority of Ki67-positive astroglia was located in the immediate vicinity of the SCI lesion and exhibited an elongated, bipolar, or radial-like shape (Fig. $3 A-F$ ). It is noteworthy that in contrast with the elongated astroglia in the mature scar borders at 14 or more days after SCI, the elongated processes of actively proliferating astroglia at $5 \mathrm{~d}$ after SCI were primarily oriented perpendicularly toward regions of tissue lesions. It is also noteworthy that these proliferating, elongated astroglia adjacent to the SCI lesions at $5 \mathrm{~d}$ after SCI had appearances reminiscent of radial or bipolar neural progenitors in vitro (Imura et al., 2006) or in forebrain proliferative zones (Garcia et al., 2004). We therefore looked for expression of various markers associated 
with neural and glial progenitors that have been reported by others to be expressed by subpopulations of reactive astroglia near CNS injuries (Frisén et al., 1995; Bannerman et al., 2007; White et al., 2010; Robel et al., 2011). In broad agreement with these reports we found that elongated astroglia in the immediate vicinity of the lesion core expressed the progenitor markers Sox2 (Fig. $3 F$ ) and nestin (Fig. 3G), and the radial glial markers Blbp (Fig. $3 F$ ) and RC2 (Fig. 3I). In contrast, elongated astroglia did not express any detectable levels of the markers LeX (CD15) or CD133 (Fig. $3 J, K$ ), which are associated with multipotent neural progenitors that can give rise to neurons and oligodendrocytes (Capela and Temple, 2002; Imura et al., 2006; Walker et al., 2013). Our findings are in agreement with the observation by others that after CNS injury or stroke, proliferating reactive astroglia have restricted potential and give rise to astroglia and do not under normal circumstance (without exogenous stimulation) give rise to neurons (Shimada et al., 2012). Our findings do not exclude that after genetic modulation or stimulation, reactive proliferating astroglial progenitors can be induced to adopt multipotent potential and give rise to neurons as well as glia in vitro and in vivo (Buffo et al., 2008; Robel et al., 2011).

We also observed proliferating astroglia in regions more distant to the lesion (1-2 mm), albeit in much smaller numbers. It is noteworthy that in contrast with the elongated phenotype of proliferating astroglia immediately adjacent to the lesion, these more distant proliferating astroglia exhibited stellate shapes while expressing Ki67, a marker of active cell division, in a manner appearing as if mature astroglia were dividing (Fig. $3 \mathrm{~L}$ ). Interestingly, although some of these proliferating stellate astroglia expressed detectable levels of nestin, they did not appear to express detectable levels of any of the other progenitor markers we examined, including Blbp, RC2, CD15, or Cd133 (data not shown).

Together, these findings showed that at early time points after SCI reactive astroglia exhibited considerable phenotypic heterogeneity as regards proliferative capacity, cellular morphology, and molecular expression, and that phenotype varied markedly with proximity or distance to the lesion core. At early stages after SCI, the tissue immediately adjacent to the lesion core contained large numbers of actively proliferating astroglia that exhibited bipolar or radial shapes with elongated processes and expressed markers of restricted glial progenitors and immature astroglia. In regions more distant to the lesion core, there were many hypertrophic stellate reactive astroglia but few actively dividing astroglia that also had stellate shapes with multiple processes and the appearance of mature astroglia.

\section{Reactive astroglia exhibit heterogeneous morphologies with respect to distance from SCI lesions throughout the period of scar formation}

We next examined a cross section of time points spanning the time course of scar formation from the period of active astroglial proliferation up to the presence of mature astroglial scar borders. Our objective in this analysis was to determine whether reactive astroglia exhibited heterogeneity of appearance in different regions near the SCI lesion throughout the time course of scar formation. To enhance the visualization of astroglial cell processes in bright field microscopy, we used simultaneous immunohistochemical staining for both GFAP and AQP4. We did this because it is well documented that GFAP visualizes only a portion of astrocyte cell processes (Fig. 1; Bushong et al., 2002; Shigetomi et al., 2013). AQP4 is a surface molecule that is located on astrocyte membranes. AQP4 is polarized to astrocyte end feet along blood vessels in healthy CNS, but after CNS injury AQP4 be-
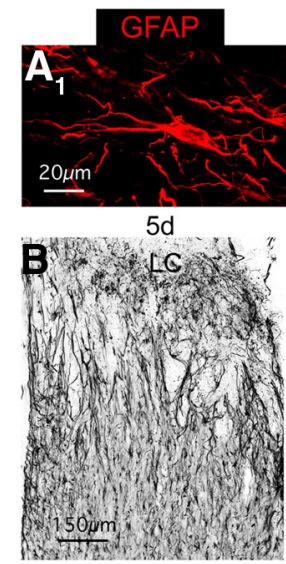

9d

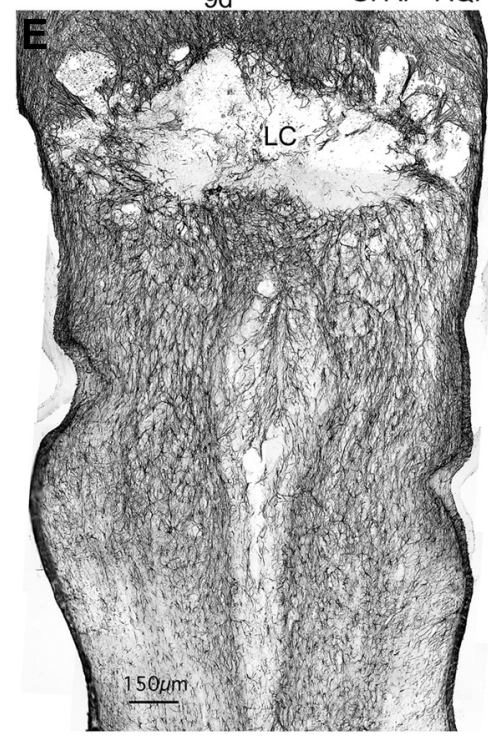

GFAP+AQP4

$7 d$
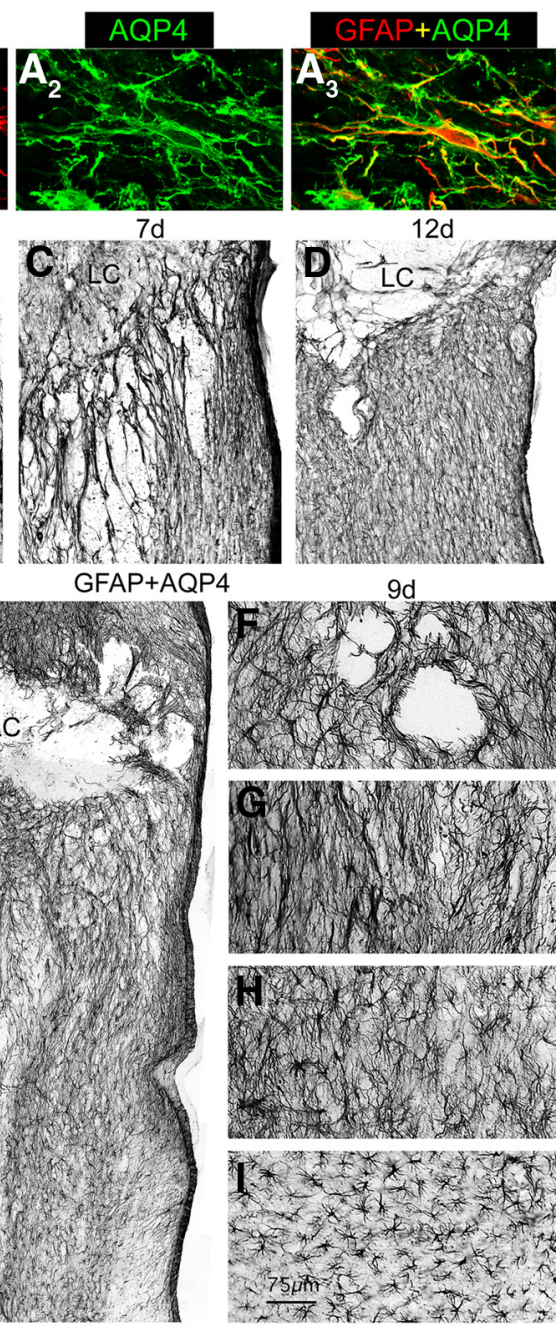

Figure 4. Throughout the time course of scar formation, reactive astroglia are heterogeneous in morphology with respect to distance from the lesion. $\boldsymbol{A}$, Multicolor fluorescence immunostaining for GFAP and AQP4 showing that after SCl, AQP4 loses its polarized distribution along astroglial end foot processes and becomes distributed evenly along the full extent of astroglial cell processes as delineated by staining for cytoskeletal GFAP. $\boldsymbol{B}-\boldsymbol{I}$, Bright-field immunostaining of GFAP + AQP4 to visualize astroglia in horizontal sections of thoracic spinal cord at $5(\boldsymbol{B}), 7(\boldsymbol{C}), 12(\boldsymbol{D})$, and $9 \mathrm{~d}(\boldsymbol{E}-\boldsymbol{I})$ after $\mathrm{SCl}$. Note that the elongated astroglial processes immediately adjacent to the $\mathrm{SCl}$ lesion and lesion core $(\mathrm{LC})$ are oriented perpendicularly to the lesion at $5(\boldsymbol{B})$ and $7 \mathrm{~d}(\boldsymbol{C})$, whereas they are oriented more parallel to the lesion at $12 \mathrm{~d}(\boldsymbol{D})$ after $\mathrm{SCl}$. Note also that whereas reactive astroglia close to the lesion are more elongated in shape reactive astroglia more distant to the lesion become progressively less elongated and more stellate in shape, as exemplified at $9 \mathrm{~d}$ in the survey, $\boldsymbol{E}$, and in the detail images, $\boldsymbol{F}-\boldsymbol{I}$, which progress from adjacent to the lesion $(\boldsymbol{F}, \boldsymbol{G})$ to more distant $(\boldsymbol{H}, \boldsymbol{I})$. Scale bars: $\boldsymbol{A}, 20 \mu \mathrm{m} ; \boldsymbol{B}-\boldsymbol{E}, 150$ $\mu \mathrm{m} ; \boldsymbol{F}-\boldsymbol{I}, 75 \mu \mathrm{m}$.

comes distributed along the surfaces of astrocyte processes (Fig. 4A; Papadopoulos and Verkman, 2013). We found that staining for GFAP + AQP4 in combination with nickel-intensified DAB provided enhanced bright field visualization of astroglial processes after SCI for both qualitative and quantitative evaluations (Figs. 4, 5).

Using simultaneous staining for GFAP + AQP4, we first examined a series of time points after SCI from early stages at $5 \mathrm{~d}$ to mature scars $21 \mathrm{~d}$ after SCI in wild-type mice. In a manner consistent with our observations described above in mature scars (Figs. 1, 3), we found that at all time points examined in wild-type or transgenic control mice, the region immediately adjacent to SCI lesion was comprised primarily of astroglia with elongated 

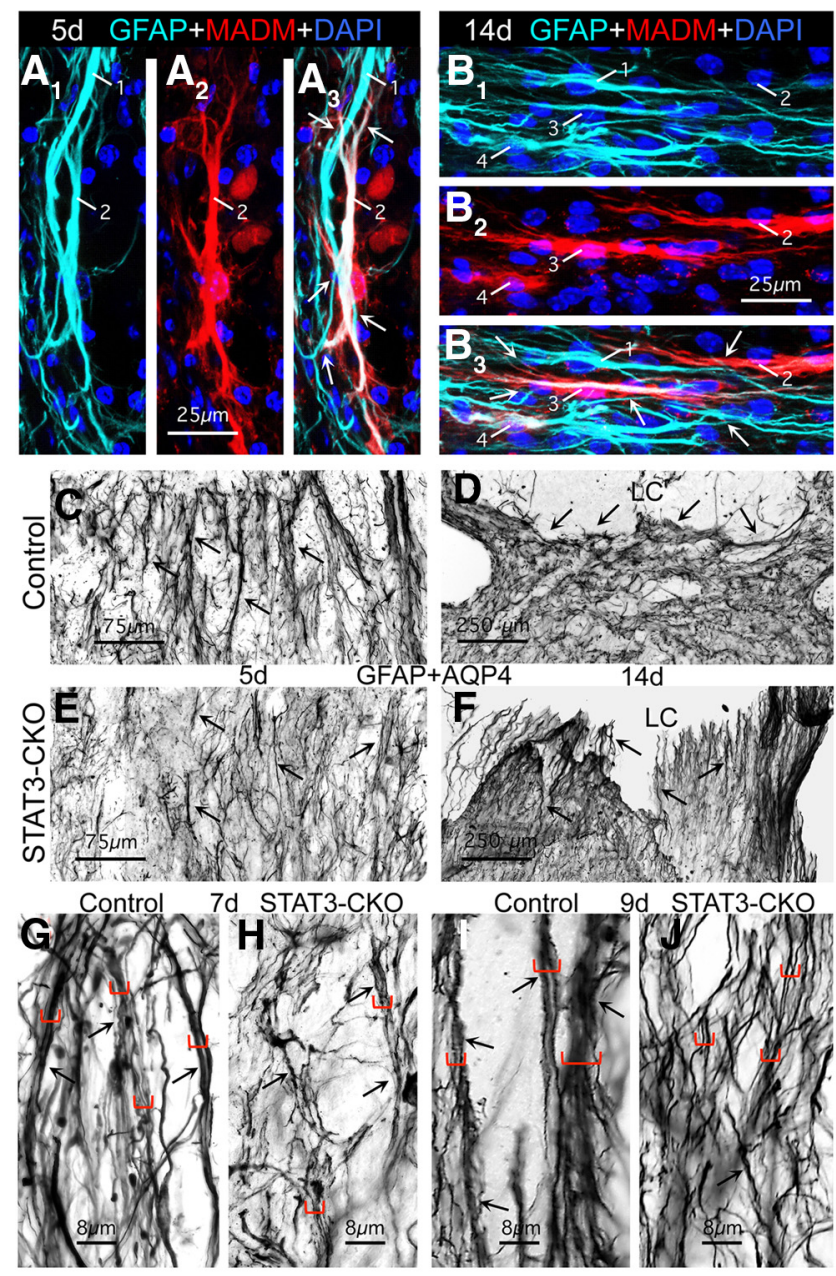

Figure 5. During the formation of astroglial scar borders, the cell processes of different elongated reactive astroglia overlap and interact extensively, and alter their orientation to the lesion over time, and these phenomena are defective in astroglia lacking STAT3. $\boldsymbol{A}, \boldsymbol{B}$, Multicolor fluorescence imaging of MADM reporter and GFAP immunostaining at $5(\boldsymbol{A})$ and $14 \mathrm{~d}(\boldsymbol{B})$ after $\mathrm{SCl}$ in the scar border zone (Z1) of mGFAP-Cre-MADM reporter mice. $\boldsymbol{A}_{\boldsymbol{1}}-\boldsymbol{B}_{1}$, Single-channel visualization of GFAP immunoreactivity, which visualizes only the astroglial cytoskeleton in light blue. $\boldsymbol{A}_{\mathbf{2}}-\boldsymbol{B}_{2}$, Single-channel visualization of MADM reporter expression, which visualizes the entire astroglial cytoplasm in red. $\boldsymbol{A}_{\mathbf{3}}-\boldsymbol{B}_{\mathbf{3}}$, Dual-channel visualization of GFAP and MADM reporter together. Numbers indicate different astroglia visible in multiple parts. Arrows indicate overlap and contacts between processes of different astroglia. Note that at both time points the lesion core (LC; not visible) is toward the top of the images such that at $5 \mathrm{~d}$ after $\mathrm{SCl}(\boldsymbol{A})$ the elongated astroglia are perpendicular, whereas at $14 \mathrm{~d}(\boldsymbol{B})$ they are parallel to the lesion. $\boldsymbol{C}-\boldsymbol{J}$, Survey and detail images of bright-field immunostaining of GFAP $+\mathrm{AQP} 4$ at $5(\boldsymbol{C}, \boldsymbol{E}), 7(\boldsymbol{G}, \boldsymbol{H})$, $9(\boldsymbol{I}, \boldsymbol{J})$, and $14 \mathrm{~d}(\boldsymbol{D}, \boldsymbol{F})$ after SCl in the scar border zone (Z1) of control $(\boldsymbol{C}, \boldsymbol{E}, \boldsymbol{G}, \boldsymbol{I})$ and STAT3-CKO $(\boldsymbol{D}, \boldsymbol{F}, \boldsymbol{H}, \boldsymbol{J})$ mice. Arrows indicate bundles where astroglial cell processes are in close contact over extended distances. Different sized brackets in $\mathbf{G}-\boldsymbol{J}$ indicated bundles of different thicknesses. Note that there are fewer thick bundles in STAT3-CKO mice at various time points and that at $14 \mathrm{~d}$ after $\mathrm{SCl}$ many astroglial processes in the scar border are oriented parallel to the central core lesion and LC in control (D) but not in STAT3-CKO $(\boldsymbol{F})$ mice. Scale bars: $\boldsymbol{A}, \boldsymbol{B}, 25 \mu \mathrm{m}$; $\boldsymbol{C}, \boldsymbol{E}, 75 \mu \mathrm{m} ; \boldsymbol{D}, \boldsymbol{F}, 250 \mu \mathrm{m} ; \boldsymbol{G}-\boldsymbol{J}, 8 \mu \mathrm{m}$.

and overlapping processes (Figs. $4 B-G, 5 A-D$ ). Interestingly, the orientation of these elongated astroglia with respect to the lesion changes over time (Figs. $4 B-D, 5 A-D$ ) as described in greater detail in the next section. In addition, at each time point, in a graded fashion with increasing distance away from the lesion, reactive astroglia became less elongated with less overlap of processes and became more stellate in shape, as illustrated for the $9 \mathrm{~d}$ time point (Fig. $4 E-I$ ), there was some reduction in staining intensity, and there was a gradual transition to the appearance of astroglia in uninjured tissue at several millimeters away from the lesion.

Together, these findings showed that throughout the progression of scar formation from 5 to $21 \mathrm{~d}$ after SCI, in the tissue around SCI, reactive astroglia were heterogeneous in their morphological phenotype and exhibited a gradient of phenotypic changes that varied with distance away from the SCI lesion core. Compared with astrocyte appearance in healthy tissue, the phenotypic changes were maximal immediately adjacent to SCI, where the majority of astroglia exhibited elongated bipolar or radial shapes, with long processes that overlapped and intermingled extensively. With increasing distance away from areas of tissue damage, the overlap of astrocyte processes diminished and transitioned into areas of astroglial hypertrophy where processes appeared to remain largely within their individual domains.

\section{Cell processes of elongated astroglia overlap and organize into scar borders in a STAT3-dependent manner over time after SCI}

To look for cellular mechanisms underlying astroglial scar formation, our next objective was to evaluate and quantitatively compare the appearance and interactions of elongated, scarforming astroglia over the time course of scar formation after SCI. To do so, we compared control mice with transgenic mice in which we have previously shown that scar formation is disrupted by selective deletion from astroglia of the signaling molecule STAT3 (Herrmann et al., 2008). These transgenic mice, referred to here as STAT3-CKO mice, were generated using a well characterized mGFAP-Cre, which after SCI targets reporter protein to over $97 \%$ of astroglia and no other identifiable cell type, and selectively deletes the signaling molecule STAT3 only from astroglia (Herrmann et al., 2008). As control mice we used mice that carried only mGFAP-Cre, or only STAT3-loxP, both of which had normal levels of STAT3 and pSTAT3 in reactive astroglia (Herrmann et al., 2008).

During qualitative evaluations in wild-type mice as described above, we noted what appeared to be a striking difference in the orientation of elongated astroglial processes with respect to immediately adjacent tissue lesions at early and late times during scar formation. Using different types of staining procedures it was clearly apparent that at early times during scar formation such as 5 and $7 \mathrm{~d}$, processes of elongated astroglia appeared oriented more or less perpendicular to nearby lesions (Figs. 3A$D, 4 B, C, 5 A, C)$, whereas in near mature or mature scars at 12,14 , or $21 \mathrm{~d}$, processes of elongated astroglia appeared oriented more or less parallel to nearby lesions (Figs. $1 C, D, J, 4 D, 5 B, D$ ). Interestingly, qualitative evaluations also strongly suggested that these apparent reorientations over time of astroglial processes with respect to nearby tissue lesions did not occur in STAT3-CKO mice, such that in these mice the astroglial processes appeared to remain more or less perpendicular to the lesions at early and late times after SCI (Fig. 5E,F).

During qualitative evaluations, we also noted using the MADM method in combination with staining for GFAP, as described above (Fig. $1 H-J$ ), that the elongated processes of different astroglia immediately adjacent to the SCI lesion were frequently in close apposition with one another, often with extensive areas of direct contact, intersection, and overlap, both early during scar formation (Fig. 5A) and in mature scars (Fig. $5 B)$. Further inspection of sections stained with GFAP + AQP4 at high magnification under oil immersion also indicated that a majority of the elongated astroglial processes immediately adjacent to tissue lesions were closely apposed for at least some dis- 


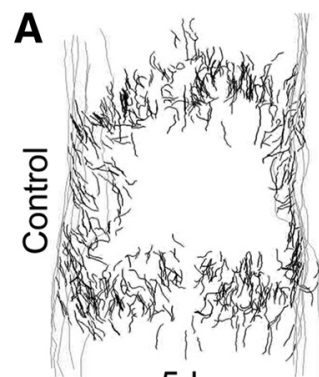

$5 d$
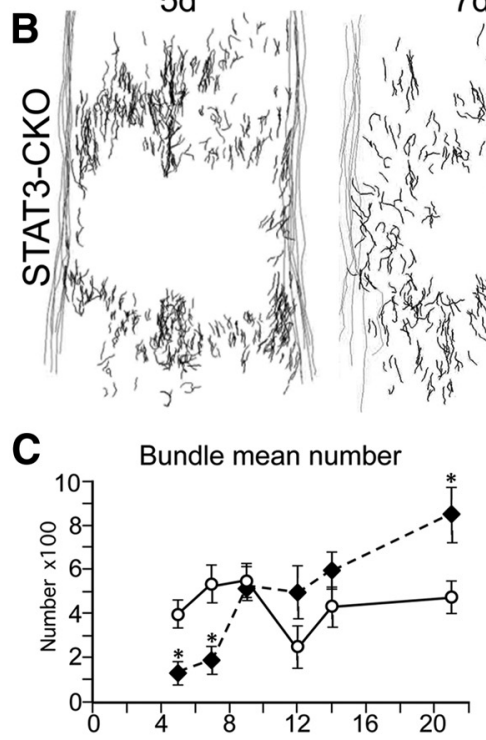

$7 d$
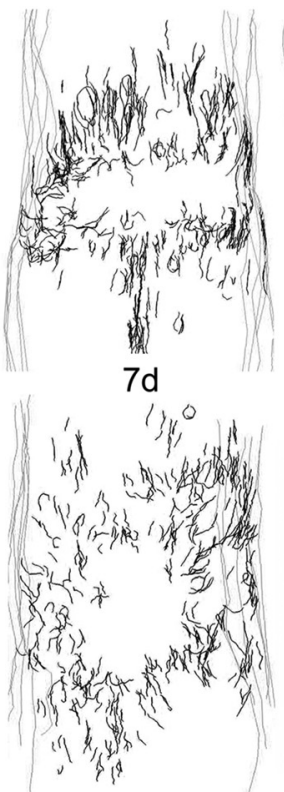

D

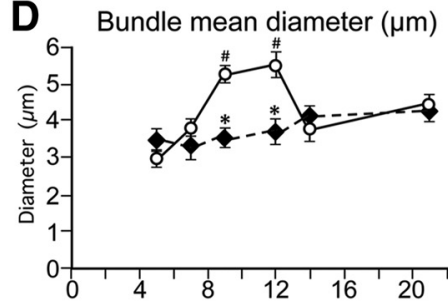

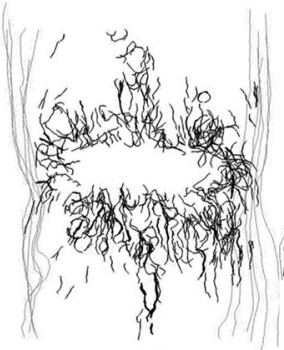

gd
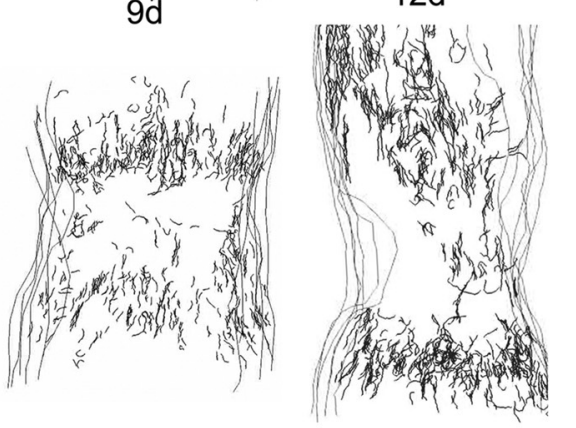

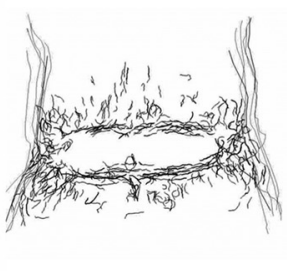

21d

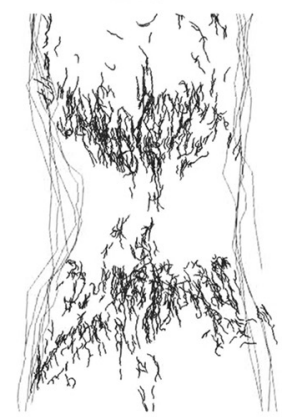

E Bundle mean angle to lesion

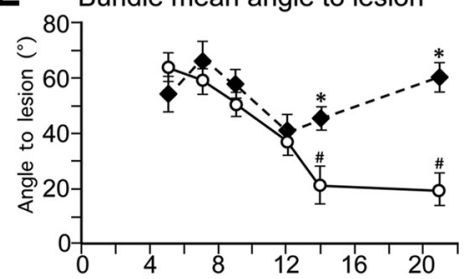

Figure 6. During the formation of astroglial scar borders, the association of astroglial cell processes into bundles and the changes in orientation of elongated reactive astroglia are quantifiably disrupted in mice with selective deletion of STAT3 from astroglia. $A, B$, Neurolucida-generated drawings of bundles formed by cell processes of elongated astroglia during the formation of astroglial scar borders at 5, 7, 9, 12, and $21 \mathrm{~d}$ after SCl in control $(\boldsymbol{A})$ and STAT3-CKO (B) mice. $\boldsymbol{C}-\boldsymbol{E}$, Graphs of data generated with Neurolucida regarding the number $(\boldsymbol{C})$, diameter $(\boldsymbol{D})$, and angle of bundles with respect to the lesion $(\boldsymbol{E})$ in control and STAT3-CKO mice as described in the text. C, STAT3-CKO at 5,7, and 21 d differ significantly from controls on the same days $\left({ }^{*} p<0.01\right)$. D, STAT3-CKO mice at 9 and $12 \mathrm{~d}$ differ significantly from controls on the same days $\left({ }^{*} p<0.01\right)$, and controls at 9 and $12 \mathrm{~d}$ differ significantly from controls at $5,7,14$, and $21 \mathrm{~d}\left({ }^{\#} p<0.01\right)$. E, STAT3-CKO mice at 14 and $21 \mathrm{~d}$ differ significantly from controls on the same days ( ${ }^{*} p<0.01$ ) and controls on 14 and $21 \mathrm{~d}$ differ significantly from controls at 5,7 , and $9 \mathrm{~d}$ ( ${ }^{\#} p<0.01$ ). ANOVA with Fisher posthoc pairwise comparison.

tance in wild-type or control mice at all time points from 5 to $21 \mathrm{~d}$ after SCI (Fig. 5C, D, G,I), and in some cases, the multiple astroglial processes appeared to coalesce into bundles of varying thickness (Fig. 5G,I). Interestingly, in STAT3-CKO mice, the formation of bundles by elongated astroglial processes adjacent to tissue lesions appeared on qualitative inspection to be disturbed (Fig. 5G,I).

We therefore conducted a detailed quantitative, computerassisted, morphometric analysis of elongated astrocyte processes in control and STAT3-CKO mice at representative times during the time course of scar formation from 5 to $21 \mathrm{~d}$ after SCI, by using the Neurolucida software program (MicroBrightField). Astroglia were immunohistochemically stained with GFAP + AQP4 and nickel-intensified DAB for topographical reconstruction and morphometric analysis (Fig. 6). For these evaluations, groupings or bundles of elongated astroglial processes were defined as areas where two or more elongated astroglial processes were in close apposition or direct contact, with at least one or more clear intersections over distances of at least $30 \mu \mathrm{m}$ or longer (Fig. 5G,I). Using the Neurolucida program, bundles of elongated astroglial processes were drawn in six horizontal sections (50 $\mu \mathrm{m}$ thick) that were evenly spaced through the middle 750 $\mu \mathrm{m}$ portion of the spinal cord (Fig. $6 A, B$ ). Section contours and bundles were identified and plotted using a combination of $\times 20$, $\times 63$, and $\times 100$ objectives using Neurolucida software. Line drawing spatial reconstructions were generated of the topographical location of the bundles of elongated astroglial processes with respect to borders of the spinal cord and the location of the SCI lesion core within $1 \mathrm{~mm}$ on either side of the central SCI lesions at various time points from 5 to $21 \mathrm{~d}$ after SCI in control mice and STAT3-CKO mice (Fig. $6 A, B$ ). In addition, we recorded and statistically compared information regarding (1) number of bundles of elongated astroglial processes, (2) approximate diameter of bundles as estimated from width of the lines required to cover bundles using Neurolucida software and $\times 100$ objectives, and (3) orientation angle of bundles of elongated astroglial processes with respect to the nearest lesion edge in the area immediately adjacent to the central SCI lesion.

(1) Bundle number: in control mice, the mean number of bundles remained more or less constant from 5 to $21 \mathrm{~d}$ after SCI and showed no significant $(p=0.95)$ trend upward or downward over time (Fig. 6C). In STAT3-CKO mice, the mean number of bundles at $5 \mathrm{~d}$ was significantly lower than that in control mice and showed a gradual but significant $(p<0.01)$ trend upward over time intersecting with controls at day 9 and reaching a significantly greater number at $21 \mathrm{~d}$ (Fig. 6C). (2) Bundle diameter: in control mice, the mean diameter of bundles increased markedly and significantly over time from 5 to $9 \mathrm{~d}$ after SCI, remained high at $12 \mathrm{~d}$ and declined again significantly by 14 and $21 \mathrm{~d}$ (Fig. $6 D)$. In STAT3-CKO mice, the mean diameter of bundles was 
similar to that of controls at $5 \mathrm{~d}$ and thereafter showed a gradual small, but significant $(p<0.01)$ trend upward without showing significant increases at 9 or $12 \mathrm{~d}$ (Fig. 6D). (3) Bundle orientation: in control mice, the mean angle of bundles with respect to an immediately adjacent lesion border was $>60$ degrees (i.e., more perpendicular to the lesion) at $5 \mathrm{~d}$ after SCI and showed a significant $(p<0.001)$ downward trend toward to $<20$ degrees (i.e., more parallel) by 14 and $21 \mathrm{~d}$ (Fig. 6E). In STAT3-CKO mice, the mean angle of bundles with respect to the nearest lesion border was $>60$ degrees (i.e., more perpendicular) at $5 \mathrm{~d}$ after SCI and thereafter did not exhibit any significant trend $(p=0.30)$ to increase or decrease over time (Fig. 6E).

These findings showed that the elongated processes of different, newly proliferated astroglia immediately adjacent to SCI interacted, organized, and reoriented over time to form compact scar borders that were aligned parallel to, and surrounded, areas of tissue damage. These activities were dependent on STAT3 signaling within the astrocytes. In this context, it is also interesting to note that in all of our different types of tissue sections evaluating different time points after SCI, we found no evidence suggestive of, or compatible with, long distance migration of either newly proliferated elongated astrocytes or of mature astrocytes. For example, we saw no changes over time in concentration gradients of different astroglial phenotypes or of newly proliferated astroglia as might be expected if such cells were moving from one location to another over time. Instead, all of our observations suggested that after SCI (1) mature astroglia remained local while becoming reactive, (2) proliferation of astroglia occurred locally, and (3) scar borders were formed as a result of STAT3-dependent interactions among newly proliferated local astroglia. Our observations were consistent with some local movement of newly generated astroglia to reorganize and reorient to align along borders of damaged tissue (Figs. 4-6) without long distance migration, in a manner compatible with reports by others using different types of transgenic analyses or in vivo imaging (Tsai et al., 2012; Bardehle et al., 2013).

\section{Mature astroglial scar borders surround inflammatory and fibrotic cells in a STAT3-dependent manner in vivo}

A number of previous loss-of-function studies have provided experimental evidence that astroglial scar formation may function to limit the spread of inflammation after CNS injury (Bush et al., 1999; Sofroniew, 2009; Haroon et al., 2011). To test this hypothesis further in the present study, we looked for evidence in vivo that the elongated astroglia that interact to form scar borders might or might not play a role in this activity. To do so we compared sections stained simultaneously for various markers of astroglia and inflammatory or fibrotic cells (Fig. 7) in control mice and STAT3-CKO mice in which the formation of scar borders by elongated astroglia is disrupted after SCI, resulting in significantly larger lesion areas (Herrmann et al., 2008). To identity inflammatory cells we stained for CD45, which is expressed by all bone marrow-derived cells. To identify fibrotic cells we stained for fibronectin, which is expressed by a variety of cell types in the multicellular lesion core. We found that after SCI in wild-type and transgenic control mice, the elongated and intertwined processes of newly proliferated scar border forming astroglia consistently aligned along borders to surround large and small lesion cores that contained CD45-positive inflammatory cells and fibronectin-positive fibrotic cells (Fig. $7 A, C, F$ ) as well as other cell types (data not shown). As quantified in the last Results section, the vast majority of inflammatory cells was confined to such lesion cores. In addition, newly proliferated scar-forming astro- glia were found to form ovoid (in 2D evaluations) structures that surrounded smaller clusters of CD45-positive inflammatory cells in various locations adjacent to lesion cores (Fig. $7 A, C, I$ ). These structures contained some, but fewer fibrotic cells (Fig. 7E). When examined by 3D analysis in thick sections, these structures exhibited globoid shapes in which clusters of CD45-positive inflammatory cells were surrounded on all sides by elongated astroglial processes that overlapped and intertwined extensively (Fig. $7 E$ ). As in the scar border along central lesion cores, the astroglia borders surrounding these ovoid or globoid structures were formed by the elongated processes of multiple different astroglia (Fig. $7 J$ ) that intertwined and overlapped extensively (Fig. $7 \mathrm{~A}, \mathrm{C}, \mathrm{H}-\mathrm{J})$. In contrast, in STAT3-CKO mice the SCI lesion consisted of a much larger, and poorly demarcated region in which inflammatory and fibrotic cells spread extensively through the tissue as shown and quantified in the last Results section. In STAT3-CKO mice, both CD45-postive inflammatory cells and fibrotic cells extended away from the central SCI lesion over long stretches into neighboring tissue and were located in between processes of astroglia that were oriented perpendicularly and did not create either a border to the lesion or borders that surrounded cell clusters (Fig. $7 B, D, G$ ).

Together, these findings showed (1) that the elongated processes of newly proliferated astrocytes surrounded large and small areas filled with inflammatory cells and fibrotic cells and (2) that this activity was dependent on STAT3 signaling within the astrocytes. These morphological observations and the differences in control and STAT3-CKO mice led us to hypothesize that newly proliferated, scar-forming astrocytes with elongated processes might act functionally to encircle and confine inflammatory and fibrotic cells in areas of severely damaged tissue, so as to separate them from nearby healthy tissue.

\section{Astroglia in vitro actively surround and corral inflammatory and fibromeningeal cells into segregated clusters and groups in a STAT3-dependent manner}

We next used an in vitro model to test the hypothesis that reactive scar-forming astroglia actively surround and segregate inflammatory and fibrotic cells. We reasoned that if scar-forming astroglia exert such activities in vivo, then they might be expected to do so in vitro. Various lines of evidence such as gene expression profiles suggest that cell cultures of primary astrocytes can be useful to study responses associated with reactive astrogliosis (Cahoy et al., 2008; Foo et al., 2011; Hamby et al., 2012). To test our hypothesis, we used primary astrocyte cell cultures that were prepared from control and STAT3-CKO mice and grown to confluence (Wanner et al., 2008; Sarafian et al., 2010; Wanner, 2012), after which we added wild-type meningeal-derived fibroblasts or macrophages to form cocultures. The primary astrocyte monocultures were used after they had become confluent (Fig. 8A) and were largely postmitotic (proliferation $<1 \%$ ) and quiescent, and after stepwise serum withdrawal and downregulation of the immaturity markers nestin and A2B5 (Wanner et al., 2008; Wanner, 2012). Monocultures from control and STAT3-CKO mice exhibited similar densities of substrate coverage (Fig. 8A). In parallel, we prepared cultures of wild-type dissociated meninges, from which we harvested meningeal fibroblasts and macrophages at different times points described in Materials and Methods (Wanner et al., 2008; Wanner, 2012). Single-cell suspensions of these meningeal cultures highly enriched for either fibroblasts or macrophages were dissociated and then added and settled onto confluent, quiescent control or STAT3-CKO astrocytes. These cocultures were allowed to interact for $2-3 \mathrm{~d}$, after which they 

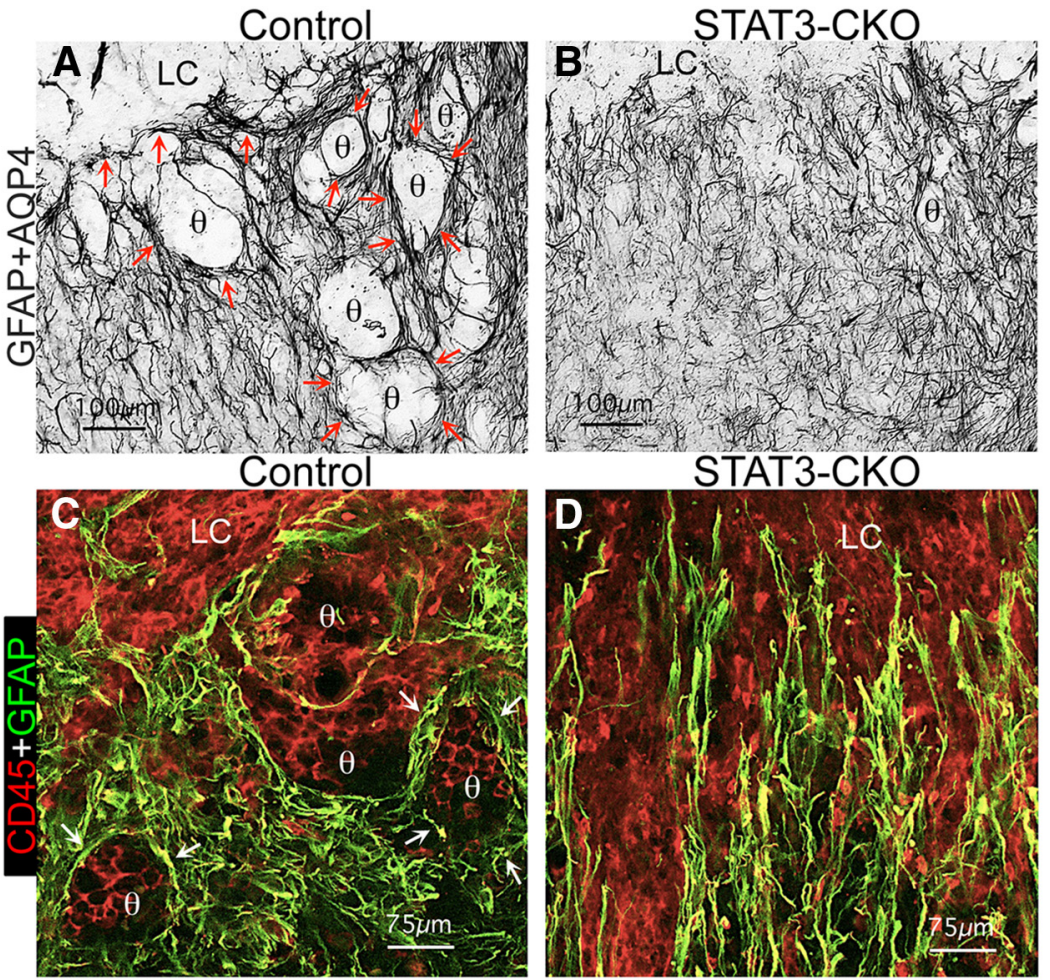

Control
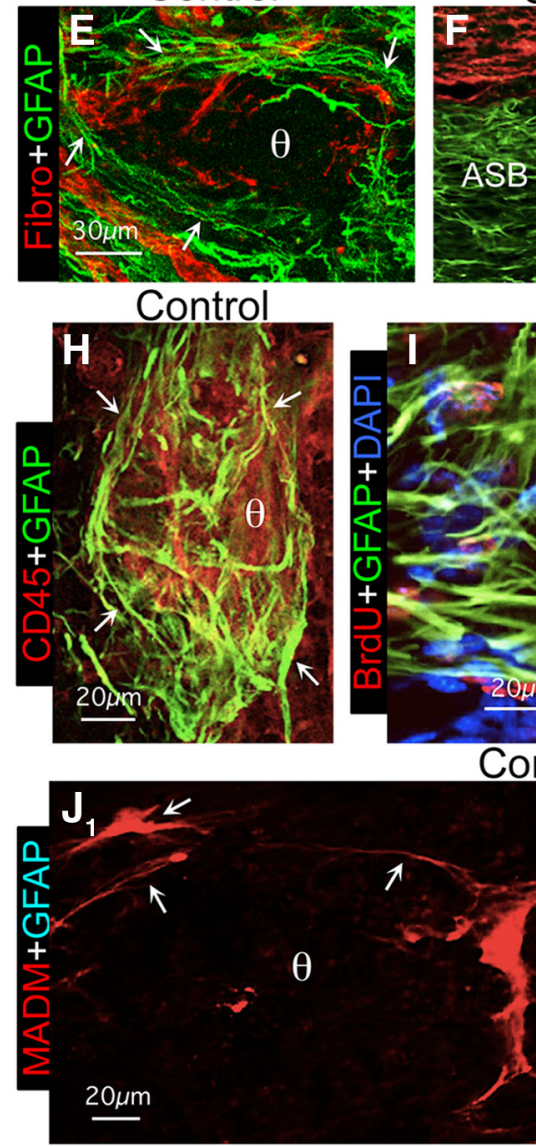

Control
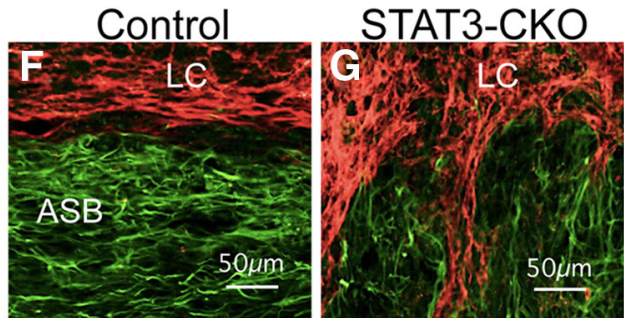

Control

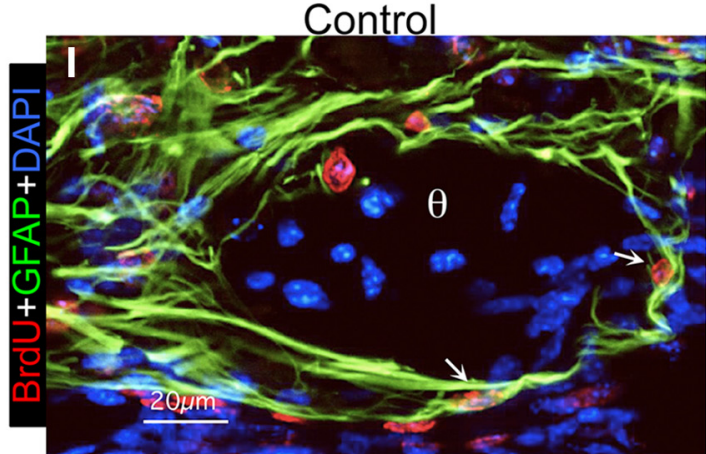

Control

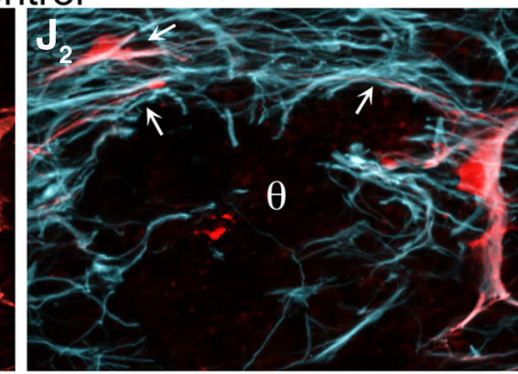

Figure 7. Mature scar borders formed by overlapping elongated astroglial surround clusters of inflammatory and fibromeningeal cells in a STAT3-dependent manner in vivo. $\boldsymbol{A}, \boldsymbol{B}$, Bright-field immunostaining of GFAP + AQP4 in the scar border zone (Z1) of control $(\boldsymbol{A})$, and STAT3-CKO $(\boldsymbol{B})$ mice. $\boldsymbol{C}-\boldsymbol{J}$, Multicolor fluorescence immunostaining for GFAP and various other markers in Z1 of control $(\boldsymbol{C}, \boldsymbol{E}, \boldsymbol{F}, \boldsymbol{H}-\boldsymbol{J})$ and STAT3-CKO $(\boldsymbol{D}, \boldsymbol{G})$ mice at $14 \mathrm{~d}$ after SCl. Note that in the control mice $(\boldsymbol{A}, \boldsymbol{C}, \boldsymbol{F}, \boldsymbol{H})$, but not STAT3-CKO mice $(\boldsymbol{B}, \boldsymbol{D}, \boldsymbol{G})$, the overlapping processes (arrows) of newly proliferated and $\operatorname{BrdU-labeled~(I)}$ elongated astroglia form borders (arrows) along the large lesion core $(\mathrm{LC})$ of the central core lesion and also around large and small circular structures $(\theta)$, which contain were fixed and cell types identified (1) astroglia with immunocytochemistry for GFAP (Figs. 8-10), (2) macrophages both by binding of biotinylated tomato-lectin and with immunocytochemistry for CD45 (Figs. $8 B, 9$ ), and (3) fibroblasts with immunocytochemistry for fibronectin (Figs. 8C,10) for qualitative and quantitative evaluations (Figs. 9C-F, 10C-F).

In confluent monocultures, astroglia were primarily epitheliod in shape with few and short cell processes in both control and STAT3-CKO cultures (Fig. 8A). When single cell suspensions of wild-type meningeal macrophages were added evenly over quiescent, confluent cultures of control astroglia, the two cell types did not intermingle randomly and over time the inflammatory cells became surrounded by dense rings of astrocytes with thin, elongated processes (Figs. 8B, 9A-C,E). It was also apparent that astroglia had changed morphology and exhibited thin, elongated processes that surrounded groups of inflammatory cells and appeared to separate or corral them into segregated cell clusters that could easily be identified and counted, and contained a far greater density of macrophages than found outside of such clusters (Figs. $8 B, 9 A-C, E$ ). In contrast, when wild-type meningeal macrophages were seeded onto cultures of STAT3-deficient astrocytes, a majority of the macrophages remained randomly intermingled with astrocytes (Figs. $8 B, 9 A, B$ ), the number of segregated clusters was reduced significantly by over $50 \%$ and the number (Fig. 9E) and the density of macrophages within clusters was reduced significantly by over $65 \%$ (Fig. $9 F$ ), even though the total area covered by macrophages remained the same (Fig. 9D).

When single cell suspensions of wildtype meningeal fibroblasts were added to newly quiescent, confluent cultures of control astroglia, the two cell types also did not intermingle randomly, and over time the fibromeningeal cells also became surrounded by dense rings of astrocytes with thin, elongated processes (Figs. $8 B, 10 A)$. In contrast, when meningeal fi-

clusters of $C D 45$-positive inflammatory $(\boldsymbol{C}, \boldsymbol{H})$ and fibronectinpositive fibromeningeal $(\boldsymbol{E})$ cells. $\boldsymbol{H}$, Thick section visualization of multiple overlapping GFAP-positive astroglial processes (arrows) in a basket-like arrangement that envelopes an ovoid cluster $(\theta)$ of CD45-positive inflammatory cells. I, BrdUpositive newly proliferated elongated astroglia (arrows) surrounding a cell cluster $(\theta) . J_{1}-J_{2}$, MADM reporter alone $\left(J_{1}\right)$ and combined with GFAP immunostaining $\left(J_{2}\right)$ reveals that the elongated cell processes surrounding circular structures $(\theta)$ derived from different astroglia (arrows). Scale bars: $A, B, 100$ $\mu \mathrm{m} ; \boldsymbol{C}, \boldsymbol{D}, 75 \mu \mathrm{m} ; \boldsymbol{E}, 30 \mu \mathrm{m} ; \boldsymbol{F}, \mathbf{G}, 50 \mu \mathrm{m} ; \boldsymbol{H}-\boldsymbol{J}, 20 \mu \mathrm{m}$. 

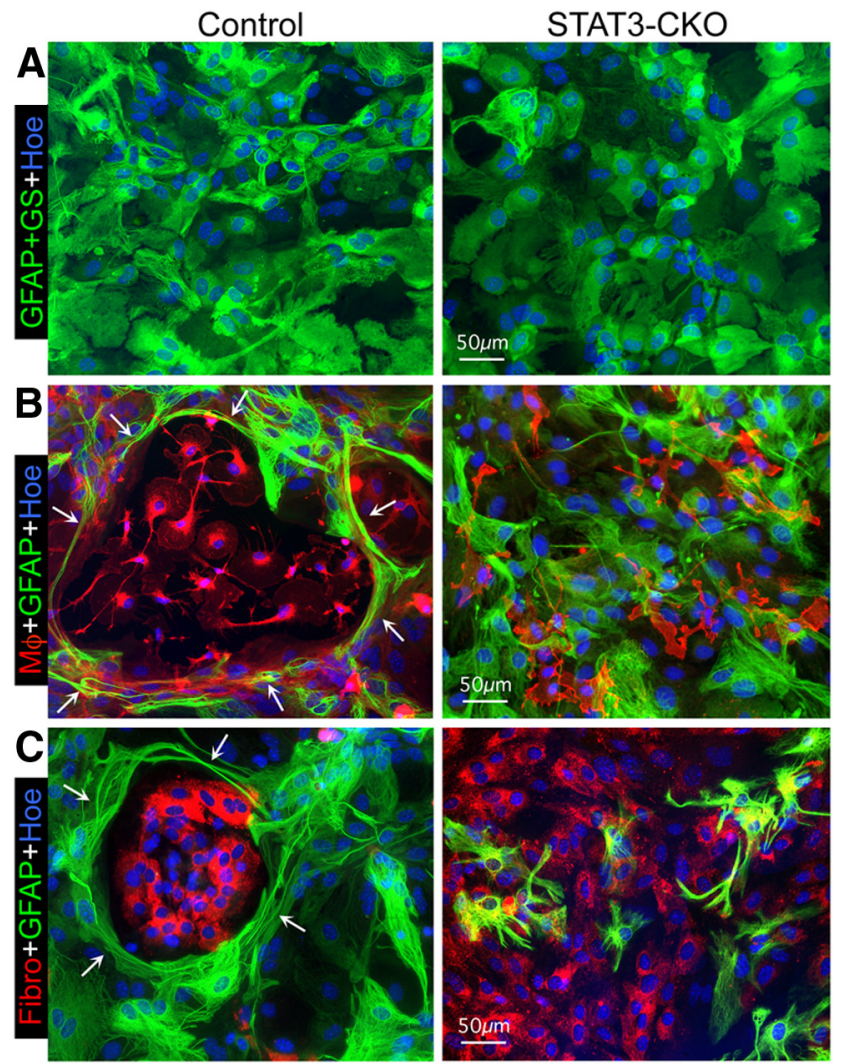

Figure 8. Astroglia in confluent monocultures become elongated and reorganize to surround newly added meningeal fibroblasts or macrophages in a STAT3-dependent manner. $\boldsymbol{A}-\boldsymbol{C}$, Multicolor fluorescence imaging of immunostaining of GFAP and GS $(\boldsymbol{A})$ or of GFAP $(\boldsymbol{B}, \boldsymbol{C})$ to visualize astroglia alone $(\boldsymbol{A})$ in combination with red tomato-lectin binding (left) or CD45 immunostaining (right) for macrophages $(\mathrm{M} \phi ; \boldsymbol{B})$ or fibronectin (Fibro) immunostaining for fibromeningeal cells $(\boldsymbol{C})$ and Hoechst (Hoe) nuclear staining. $\boldsymbol{A}$, Shows confluent monocultures of both control and STAT3-CKO astroglia. $\boldsymbol{B}, \boldsymbol{C}$, Shows cocultures at $2 \mathrm{~d}$ after macrophages $(\boldsymbol{B})$ or fibromeningeal cells ( $\boldsymbol{C}$ ) have been added to confluent control or STAT3-CKO astroglia. Note that after addition of either cell type to control cultures (left), astroglia display elongated processes (arrows) that surround and enclose the added cells in circular structures. In contrast, STAT3-CKO astroglia (right) fail to form circular structures or surround the added cells, but instead the added cells intermingle among the astroglia (B, $)$. Scale bars: $\boldsymbol{A}-\boldsymbol{C}, 50 \mu \mathrm{m}$.

broblasts were seeded onto STAT3-deficient astroglia (Figs. $8 C, 10 A, B)$ the number of fibroblasts and the total area covered by fibroblasts increased significantly by over $60 \%$ (Fig. $9 D$ ). In addition, the total number of segregated clusters of fibroblasts was reduced significantly by over $50 \%$ (Fig. $9 E$ ) together with a significant increase in large clusters and a significant decrease in small clusters (Fig. 9E), while the density of fibroblasts within clusters remained the same (Fig. $9 F$ ).

These findings show that when quiescent astroglia in cell culture are confronted with macrophages or fibromeningeal cells, the astroglia changed their morphology and elaborated thin elongated processes and actively surrounded inflammatory and fibromeningeal cells and corralled them into discrete, segregated clusters. This activity was dependent on STAT3 signaling within the astrocytes. In addition, whereas astroglia did not seem to influence the expansion (total area covered) by macrophages, the area covered by fibromeningeal cells was significantly and substantially greater in STAT3-CKO cultures, suggesting that control astroglia regulated and limited the expansion of meningeal fibroblasts in a STAT3-dependent manner.
STAT3-deficient astroglia fail to form functional scar borders after SCI in vivo, leading to increased inflammatory cells and decreased neurons in adjacent tissue

Last, we tested the hypothesis that scar borders formed by newly proliferated elongated astroglia in vivo function to restrict the spread of inflammatory cells away from foci of severely damaged tissue into neighboring tissue that contains viable neurons. This hypothesis is based on previous observations that ablation of proliferating scar-forming astrocytes increases the spread of inflammatory cells and increases the size of tissue lesions (Bush et al., 1999; Faulkner et al., 2004) and that astroglial STAT3-CKO mice exhibit larger lesion volumes and reduced behavioral recovery after SCI (Herrmann et al., 2008). To extend these observations in the present study, we correlated at the cellular level the overlap of scar-forming and reactive astroglia with viable neurons and inflammatory cells in specific zones (Z1-Z4) located at various distances up to $2 \mathrm{~mm}$ adjacent to lesion borders in control and STAT3-CKO mice (Figs. 11, 12) in a manner similar to that described above for GFAP-TK and BrdU-positive cells. Viable neurons were identified by staining for NeuN. Inflammatory cells were identified by staining for CD45, which visualizes resident microglia, infiltrating macrophages, and lymphocytes, as well as fibrocytes (Sroga et al., 2003; Aldrich and Kielian, 2011; Reilkoff et al., 2011), which we found associated with lesion cores. It is noteworthy that in tissue spreading away from the lesion core, STAT3-CKO mice exhibited pronounced increases relative to control mice in the presence of CD45-positive cells of different kinds including globoid infiltrating inflammatory cells and clusters of fibrocytes (Figs. 11G,H, 12D, E).

Cell counts of NeuN-positive neurons in control mice showed that there were reduced, but substantial numbers of viable neurons in close proximity (Z1 and Z2) of SCI lesion borders (Fig. $12 A, C, G)$, where they overlapped with, and were intermingled among, elongated scar-forming astroglia (Fig. $11 A, E, I$ ), but not with CD45-positive globoid, infiltrating inflammatory cells (Fig. $11 A, E, G)$. Cell counts in control mice further showed that essentially normal densities of NeuN-positive neurons were present within a $1-2 \mathrm{~mm}$ distance (Z3 and $\mathrm{Z4}$ ) from the lesion (Fig. $12 A, C, G)$. In contrast, in STAT3-CKO mice there were few NeuN-positive neurons in close proximity (Z1 and Z2) of the lesion (Fig. $12 B, C, H$ ), and the density of neurons remained significantly reduced at 1 and $2 \mathrm{~mm}$ distance (Z3 and $\mathrm{Z4}$ ) from the lesion (Fig. 12 B, C,H). In addition, it is noteworthy that the densities of CD45-positive inflammatory cells in different locations adjacent to the SCI lesion were the mirror opposite of the densities of NeuN in both control and mGFAP-STAT3-CKO mice (Fig. 11). In control mice, there were small numbers of CD45positive cells, and high densities of astroglia in Z1 and Z2 immediately adjacent to the lesion (Fig. $11 A, C, G, K$ ), and few to none in $\mathrm{Z3}$ and $\mathrm{Z} 4$ at a $1 \mathrm{~mm}$ or $2 \mathrm{~mm}$ distance from the lesion (Fig. $12 D, F, I)$. In contrast, in mGFAP-STAT3-CKO mice there were large numbers CD45-positive cells and low densities of astroglia in the immediate vicinity of the lesion and the density remained significantly elevated at 1 and $2 \mathrm{~mm}$ away (Fig. $11 \mathrm{~B}, D, H, L$ ) and many CD45-positive inflammatory cells were found in Z3 and Z4 at $1 \mathrm{~mm}$ or $2 \mathrm{~mm}$ distance from the lesion (Fig. $12 E, F, J$ ).

These findings showed that there was (1) a positive correlation between the presence of scar-forming, reactive astroglia, and viable neurons; (2) a negative correlation between the presence of scarforming, reactive astroglia, and inflammatory cells; and (3) a negative correlation between the presence of inflammatory cells and viable neurons in tissue adjacent to SCI. These findings also showed that disruption of astroglial scar formation in mGFAP-STAT3-CKO 
mice led to increased spread of inflammatory cells and decreased survival of neurons in tissue adjacent to SCI. Together, these findings provide strong evidence in support of the notion that scar forming and reactive astroglia function to limit the spread of inflammatory cells from sites of severe tissue damage into healthy adjacent tissue.

\section{Discussion}

In this study, we define how newly proliferated astroglia interact and organize into scars that surround and isolate tissue lesions over an extended period of days after a focal traumatic injury. Our findings show that (1) adjacent to crush SCI, reactive astrocytes are heterogeneous in phenotype as regards proliferation, morphology, and chemistry in a manner that varies with distance from the lesion; (2) mature scar borders are comprised primarily of newly proliferated astroglia with elongated cell processes; (3) during scar formation around large and small areas of severely damaged tissue, the cell processes of different elongated astroglia associate into overlapping bundles that quantifiably reorient and organize via STAT3dependent mechanisms to form dense mesh-like arrangements; (4) confluent astroglia in vitro actively surround inflammatory and fibromeningeal cells and corral them into segregated groups via STAT3dependent mechanisms; (5) newly proliferated scar-forming astroglia in vivo surround inflammatory and fibrotic cells via STAT3dependent mechanisms in such a manner that largely segregates these cells from nearby tissue containing viable neurons; and (6) when formation of scar borders by astroglia is disrupted by deletion of STAT3, there is increased inflammation and decreased neuronal survival in neighboring neural tissue. These findings advance emerging concepts about the phenotypic heterogeneity, cellular interactions, signaling mechanisms, and adaptive functions of reactive astrogliosis and scar formation after SCI.

\section{Reactive astroglia exhibit gradients of phenotypic heterogeneity adjacent to SCI}

Accumulating evidence indicates that re-

active astrogliosis is not a simple all or none response, but instead is highly and specifically variable as regards changes in cell morphology, proliferation, and molecular expression, which are tuned in a context-specific manner to different CNS insults (Hatten et al., 1991; Norton et al., 1992; Wilhelmsson et al., 2006; Oberheim et al., 2008; Sofroniew, 2009; Hamby et al., 2012; Zamanian et al., 2012). Here, we extend this concept by showing that after SCI, reactive astroglia exhibit phenotypic heterogeneity in all three of these parameters in a manner that is graded with
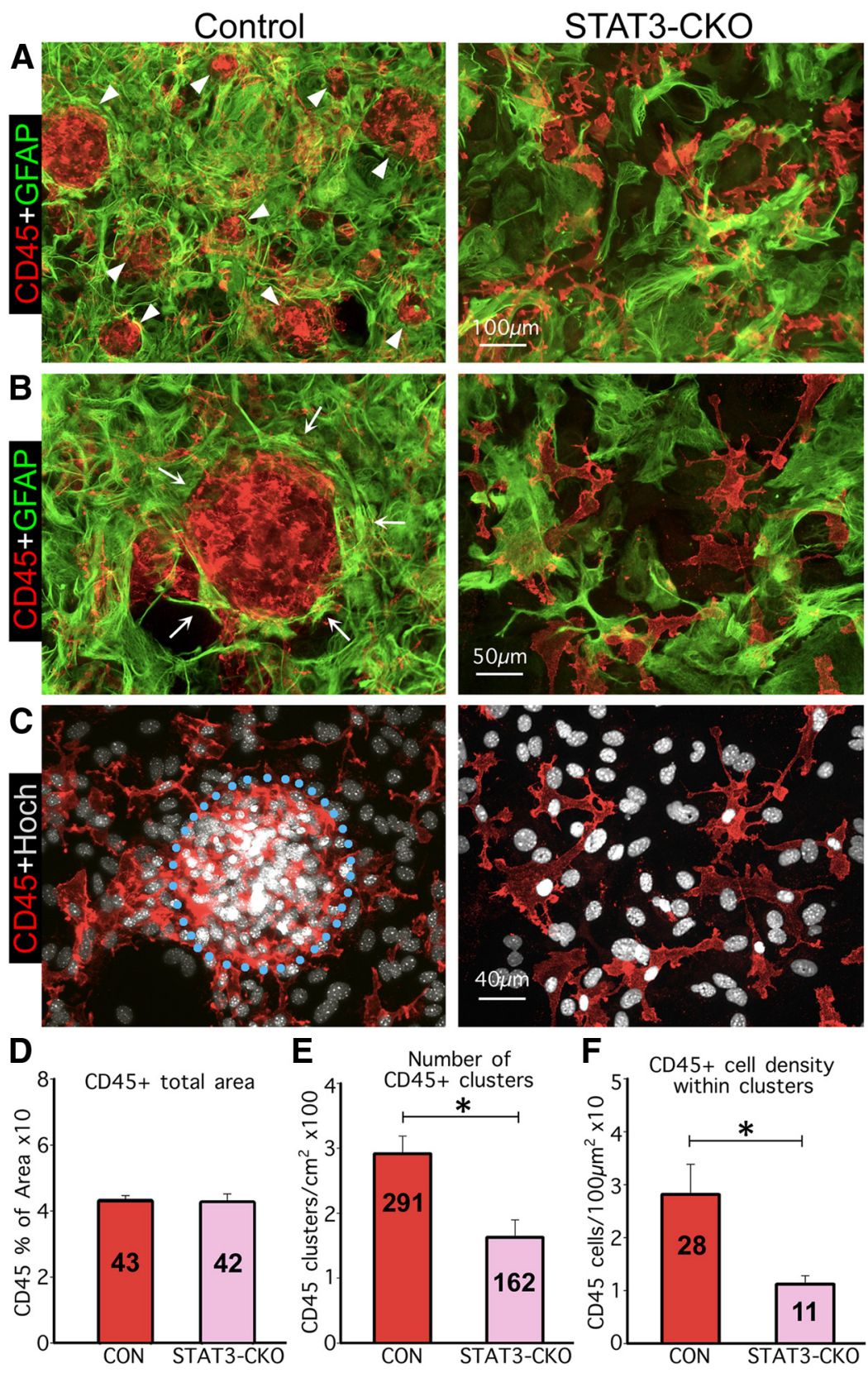

Figure 9. In cocultures, elongated astroglia segregate macrophages into discrete clusters and this activity is quantifiably disrupted by selective deletion of STAT3 from astroglia. $\boldsymbol{A}-\boldsymbol{C}$, Multicolor immunofluorescence imaging of GFAP and CD45 $(\boldsymbol{A}, \boldsymbol{B})$ or CD45 immunostaining plus Hoechst (Hoch) nuclear staining (C). A, B, Show at low $(\boldsymbol{A})$ and high $(\boldsymbol{B})$ magnification that in controls (left), elongated astroglial processes (arrows) surround and enclose macrophages in circular structures (arrowheads) of various sizes. In contrast, the processes of STAT3-CKO astroglia (right) fail to form circular structures or surround macrophages. C, Shows macrophages and nuclei of the same areas in $\boldsymbol{B}$, emphasizing their higher density and clustering in cocultures with control astroglia (left) compared with their more scattered distribution in cocultures with STAT3-CKO astroglia (right). D-F, Graphs showing quantitation of CD45-positive areas (D), number of CD45-p0sitive macrophage clusters $(\boldsymbol{E})$, and cell density within macrophage clusters $(\boldsymbol{F})$, in cocultures of astroglia and macrophages; $n \geq 3$ animals per genotype. ${ }^{*} p<0.001$ ( $t$ test). Scale bars: $\boldsymbol{A}, 100 \mu \mathrm{m} ; \boldsymbol{B}, 50 \mu \mathrm{m} ; \boldsymbol{C}, 40 \mu \mathrm{m}$.

respect to distance from lesions. Our findings show that there are at least two broad categories of reactive astroglia that are fundamentally different: (1) newly proliferated, elongated astroglia that have extensively overlapping and interacting cell processes that form scar borders and (2) hypertrophic stellate reactive astroglia that for the most part are not proliferative and derive directly from mature local astroglia, and whose processes overlap far less extensively or remain within their original territories. These broad categories of structural heterogeneity do not pre- 

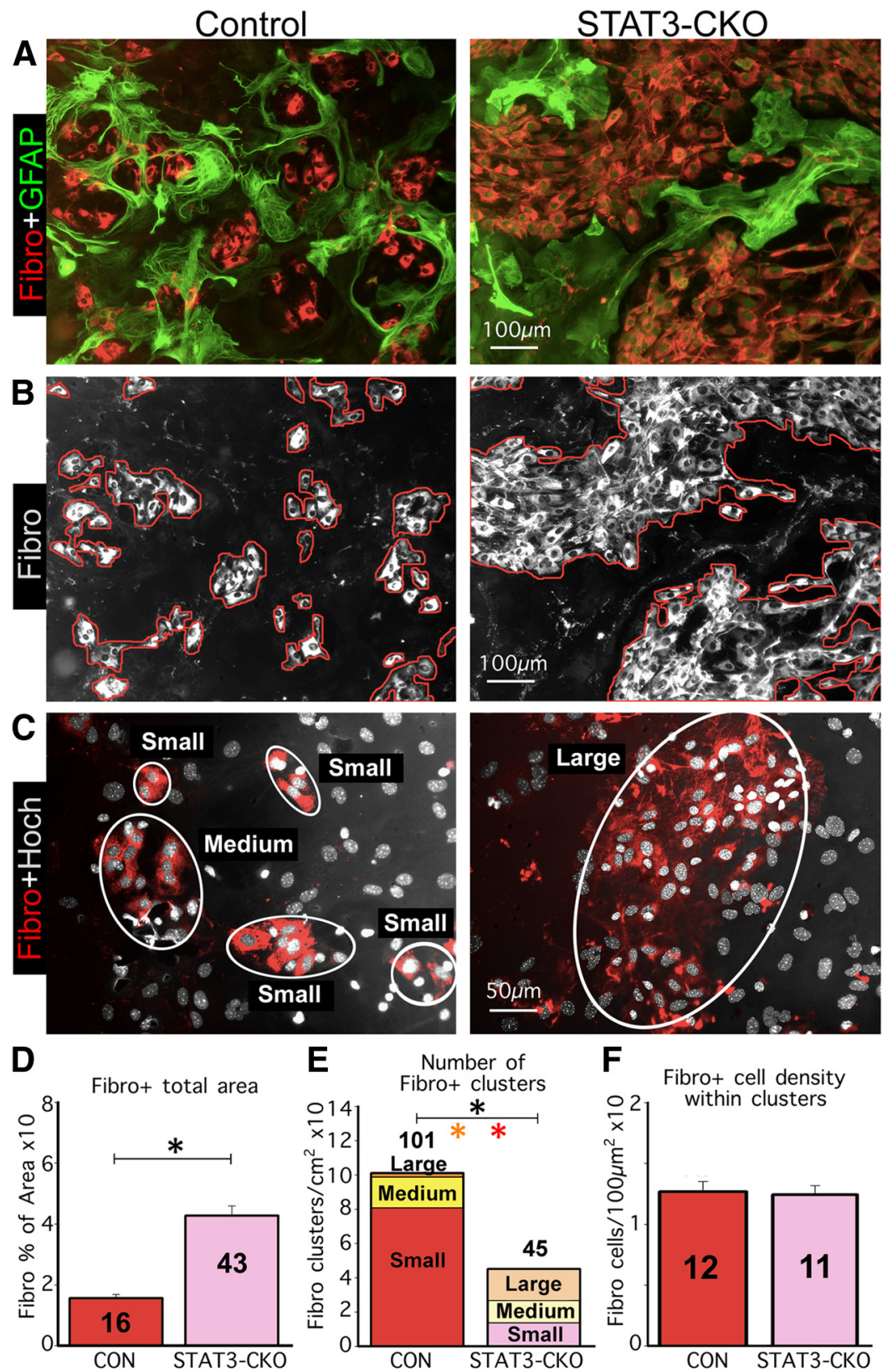

Figure 10. In cocultures, elongated astroglia segregate fibromeningeal cells into discrete clusters and this activity is quantifiably disrupted by selective deletion of STAT3 from astroglia. $A-C$, Multicolor immunofluorescence imaging of GFAP and fibronectin $(\boldsymbol{A})$ or fibronectin immunostaining plus Hoechst (Hoch) nuclear staining $(\boldsymbol{B}, \boldsymbol{C})$. $\boldsymbol{A}$, Shows that in controls (left), elongated astroglial processes surround and enclose fibromeningeal cells in circular structures of various sizes. In contrast, the processes of STAT3-CKO astroglia (right) fail to form circular structures but instead intermingle among groups of fibromeningeal cells. B, Shows fibromeningeal cells (white) of the same areas in $A$ and illustrates tracing (red lines) used to quantify area covered by meningeal fibroblasts. C, Illustrates how fibromeningeal cells were categorized into clusters (white rings) of various sizes for quantification. Note that in control cocultures, fibromeningeal cells were present mostly in small and medium sized clusters, whereas in STAT3-CKO cocultures fibromeningeal cells were in fewer and generally much larger cell clusters. $\mathbf{D}-\boldsymbol{F}$, Graphs showing quantitation of fibronectinpositive areas $(\boldsymbol{D})$, number of fibromeningeal cell clusters of various sizes $(\boldsymbol{E})$, and cell density within fibromeningeal cell clusters $(\boldsymbol{F})$, in cocultures of astroglia and fibromeningeal cells; $n \geq 3$ animals per genotype. ${ }^{*} p<0.001$ ( $t$ test) for total clusters in black and for large or small clusters in colors. Scale bars: $A, B, 100 \mu \mathrm{m} ; C, 50 \mu \mathrm{m}$.

clude additional levels of heterogeneity, such that neighboring reactive astroglia have been reported to exhibit specific differences in molecular expression (Zhang and Barres, 2010; Hamby et al., 2012). Such observations raise important questions about the signaling mechanisms that might result in such heterogeneity or in gradients of cellular changes, as well as about the different functions and effects that might be associated with different phenotypes of reactive astroglia.

Signaling mechanisms that determine heterogeneous aspects of reactive astrogliosis are incompletely understood (Sofroniew, 2009). Newly proliferated reactive astroglia have for some time been associated with penetrating CNS lesions that disrupt the blood-brain barrier (BBB) and not with $\mathrm{CNS}$ insults where $\mathrm{BBB}$ function is preserved (Hatten et al., 1991; Norton et al., 1992; Bush et al., 1999; Sofroniew, 2009). Astroglial proliferation is also observed around clusters of infiltrating inflammatory cells during autoimmune inflammation (Voskuhl et al., 2009). Numerous molecular regulators of reactive astroglial proliferation and other phenotypic changes have been proposed, in large part based on in vitro studies (Sofroniew, 2009). Our demonstration here that differences in reactive astroglial phenotype in vivo vary in direct proportion to distance from SCI lesions suggests potential roles for lesion-derived diffusible morphogens that could gain $\mathrm{CNS}$ access from serum at sites of disrupted BBB or could be secreted by collections of inflammatory or fibrotic cells in SCI lesion cores. Serum proteins such as thrombin, fibrinogen, and albumin, and growth factors, cytokines, and other inflammatory mediators produced by blood-borne and injury-associated cells, are able to influence astroglial intracellular signaling, transcription, proliferation, and function (Gadea et al., 2008; Sofroniew, 2009; Schachtrup et al., 2010; Hamby et al., 2012). Gradients of diffusible morphogens regulate the emergence of cell phenotype during CNS development (Jessell, 2000). Our findings point toward the potential for morphogen gradients arising from focal sites of $\mathrm{BBB}$ disruption and collections of inflammatory and fibrotic cells to influence CNS repair and recovery of function after insults such as trauma, stroke, or autoimmune disease. Manipulating such gradients may represent a strategy to improve outcome.

\section{Scar borders are formed by STAT3- dependent organization of newly proliferated elongated astroglia} One of our main objectives in this study was to identify phenotypic characteristics and cellular interactions of the astroglia that establish the scar border. Previous studies have shown that astroglia scar formation is substantively disrupted by the ablation of proliferating astroglia (Bush et al., 1999; Faulkner et al., 2004) as well as by the deletion of STAT3 signaling from astroglia (Herrmann et al., 2008). Here, we extend these observations in several ways. We show that the mature scar borders that imme- 

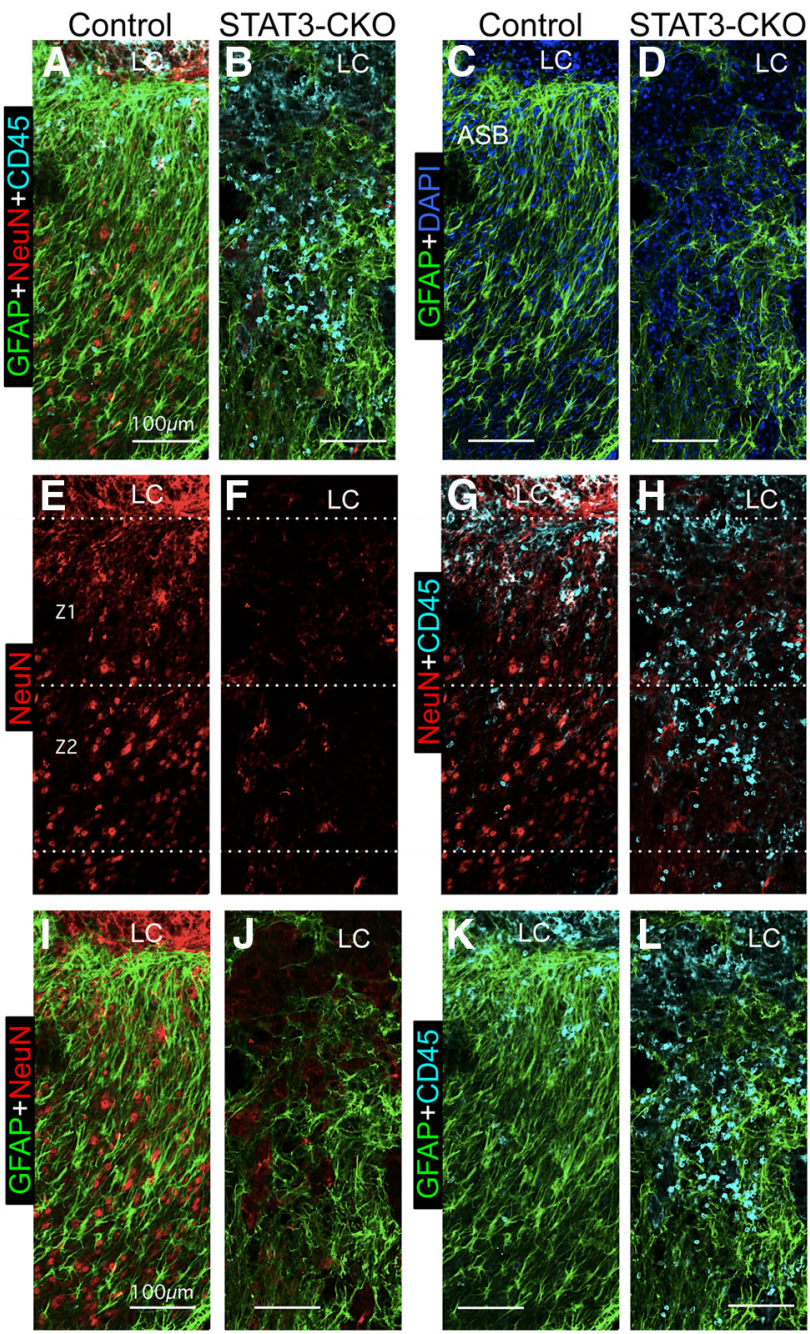

Figure 11. In vivo, many healthy neurons and few inflammatory cells overlap with astroglial scar borders adjacent to SCl lesions in control mice, whereas in STAT3-CKO mice few neurons and many inflammatory cells overlap with astroglial borders adjacent to SCI lesions. $A-L$, Multicolor fluorescence immunostaining for GFAP, NeuN, and CD45 in Z1 and ZZ adjacent to the central lesion core and lesion core (LC) at $14 \mathrm{~d}$ after $S \mathrm{Cl}$ in control $(\boldsymbol{A}, \boldsymbol{C}, \boldsymbol{E}, \boldsymbol{G}, \boldsymbol{I}, \boldsymbol{K})$ and STAT3-CKO $(B, D, F, H, J, L)$ mice. The pairs of images show the same fields in the control and STAT3-CKO mice using different combinations of fluorescent filters so as to compare locations and overlap of different cell types: $A, B$, Astroglia (GFAP), neurons (NeuN), and inflammatory cells (CD45) are shown together. $\boldsymbol{C}, \boldsymbol{D}$, Same fields as in $\boldsymbol{A}$ and $\boldsymbol{B}$ showing astroglia only; note the prominent astroglial scar border (ASB) adjacent to the $L C$ in the control $(C)$ and the failure of astroglia to form a scar border adjacent to the LC in STAT3-CKO (D).E, F, Same fields showing neurons only; note the much greater number of NeuN-positive neurons in $\mathrm{Z1}$ and $\mathrm{Z} 2$ in control $(\boldsymbol{E})$ compared with STAT3-CKO ( $\boldsymbol{F}) . \boldsymbol{G}, \boldsymbol{H}$, Same fields showing neurons and inflammatory cells; note that areas with neurons contain few or no inflammatory cells in control $(\boldsymbol{G})$, whereas areas filled with inflammatory cells in STAT3-CKO contain few neurons $(\boldsymbol{H})$. $\boldsymbol{I}, \boldsymbol{J}$, Same fields showing astroglia and neurons, which intermingle in control $(\boldsymbol{I})$ but not STAT3-CKO (J). $\boldsymbol{K}, \boldsymbol{L}$, Same fields showing astroglia and inflammatory cells; note that there are few inflammatory cells intermingled with astroglia in control $(\boldsymbol{K})$ but that inflammatory ells are prominent in areas devoid of astroglia in STAT3-CKO (L). Scale bars: $A-L, 100 \mu \mathrm{m}$.

diately interface with and surround damaged CNS tissue are comprised primarily of relatively narrow zones of newly proliferated astroglia and that astroglial proliferation diminishes rapidly with distance from tissue lesions. These newly proliferated scarforming astroglia have elongated shapes with long cell processes that quantifiably interact, reorient, and organize in a STAT3dependent manner during scar formation. Early during scar border formation, these elongated astroglia are oriented more or less

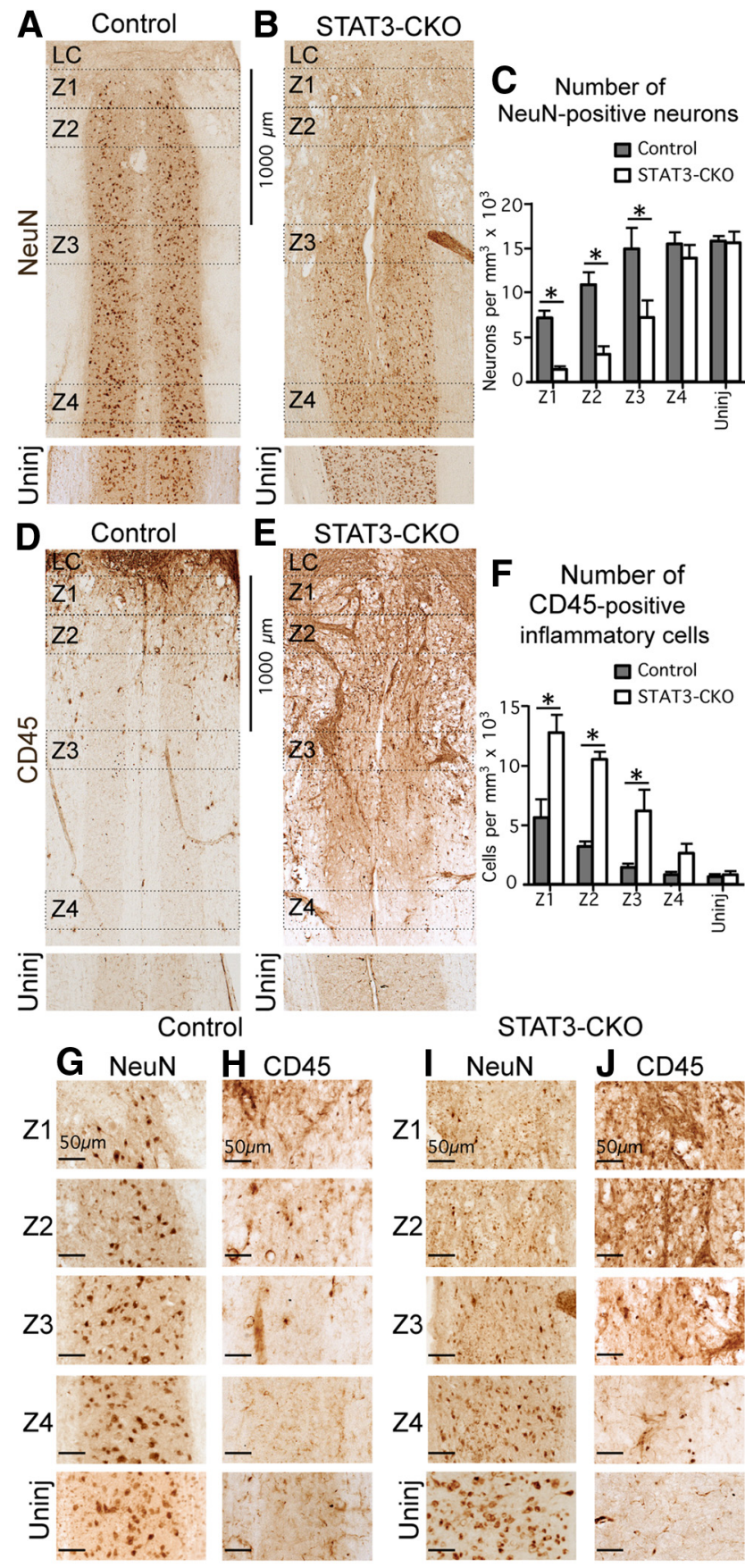

Figure 12. In mice with selective deletion of STAT3 from astroglia, the density of neurons is significantly lower and the density of inflammatory cells is significantly higher in tissue adjacent to the $S C l$ lesion core. $A, B, D, E$, Bright-field immunostaining showing survey images of NeuN $(\boldsymbol{A}, \boldsymbol{B})$ and $C D 45(\boldsymbol{D}, \boldsymbol{E})$ in Z1-Z4 adjacent to the central lesion core and lesion core $(\mathrm{LC})$ at $14 \mathrm{~d}$ after SCl in control $(\boldsymbol{A}, \boldsymbol{D})$ and STAT3-CKO $(\boldsymbol{B}, \boldsymbol{E})$ mice. $\boldsymbol{C}, \boldsymbol{F}$, Graphs showing the Neu-N-positive neurons $(\boldsymbol{C})$, and $(\mathrm{D} 45$-positive globoid inflammatory cells $(\boldsymbol{F})$ in $\mathrm{Z1}-\mathrm{Z4}$ after $\mathrm{SCl}$ and in uninjured tissue in control and STAT3-CKO mice ( $n=4$ per group). ${ }^{*} p<0.05$ (ANOVA with post hoc pairwise Bonferroni comparison). $\mathbf{G}-J$, Detail images of NeuN-stained neurons $(\mathbf{G}, \boldsymbol{I})$ and $(D 45$ stained inflammatory cells $(\boldsymbol{H}, \boldsymbol{J})$ taken from survey images in $\boldsymbol{A}, \boldsymbol{B}, \boldsymbol{D}$, and $\boldsymbol{E}$. Note the greater loss of neurons and greater number of inflammatory cells in Z1-Z3 in STAT3-CKO compared with control mice. Scale bars: $A, B, D, E, 1000 \mu \mathrm{m} ; \boldsymbol{G}-J, 50 \mu \mathrm{m}$.

perpendicular to lesions and as scar formation progresses, they quantifiably reorient to become more or less parallel to the lesion. It is noteworthy that the initial perpendicular orientation of the elongated astroglia we observed here at 5-9 d after SCI appears remarkably similar to that of palisading astroglia reported per- 
pendicular to cortical lesions at 1 week after traumatic injury and implicated in post-traumatic epileptic foci (Oberheim et al., 2008). Our findings suggest that these palisading astrocytes may be newly proliferated, elongated scar-forming astroglia. We also show that during scar border formation, elongated astroglial cell processes interact in bundles that overlap and intertwine as they surround and envelop the lesions. Bundled meshworks of aligned elongated immature astrocytes have been described in the developing brain and suggested to act as tract-forming pathways (Silver et al., 1993), which may link developmental functions of astroglia with their effects on axon regrowth after CNS injury (Silver and Miller, 2004; Li et al., 2012). In this regard it will be of interest in the future to examine (1) the potential formation of junctions among astroglial cell processes during scar formation, which may show similarity to junction formation among immature glia (Wanner and Wood, 2002; Wanner et al., 2006) and (2) the production by astroglia of molecules potentially inhibitory to cell or axon migration, in correlation with the time course of scar formation.

Our findings that elongated scar-forming astroglia express certain markers associated with progenitors or radial glia such as nestin, RC2, Blbp, and SOX2 are in agreement with previous reports and extend these reports to show that these cells do not express markers associated with multipotent neuronogenesis such as CD15 or CD133 (Frisén et al., 1995; Capela and Temple, 2002; Komitova and Eriksson, 2004; Imura et al., 2006; Bannerman et al., 2007; White et al., 2010; Robel et al., 2011; Walker et al., 2013). We did not investigate the origin or cell lineage of these newly proliferating, elongated scar-forming astroglia, but began with the observation of their presence along the edges of lesions of severely damaged tissue and then followed their organization into scar borders around damaged tissue. It deserves mention that this organization occurred without obvious evidence for long distance migration, similar to reports using different transgenic analyses or in vivo imaging to show local derivation and minimal migration of newly generated reactive astroglia after CNS injury (Tsai et al., 2012; Bardehle et al., 2013).

\section{Scar-forming astroglia surround and corral inflammatory and fibrotic cells and segregate these cells from tissue with viable neurons}

Although astroglial scar formation has been recognized for over 120 years, its adaptive functions have been poorly understood. Previous transgenically targeted loss-of-function studies have shown that disruption of astroglia scar formation results in increased spread of inflammation, increased tissue damage, and reduced functional recovery after various CNS insults (Bush et al., 1999; Faulkner et al., 2004; Herrmann et al., 2008; Voskuhl et al., 2009). Our findings here extend these observations by showing that during scar border formation in vivo, the elongated processes of newly proliferated astroglia quantifiably interact and reorient to surround inflammatory and fibrotic cells in large and small clusters. We further show in vitro, that astroglia with elongated processes spontaneously surround inflammatory and fibromeningeal cells and corral them in to separated cell clusters. Moreover, the corralling activity whereby astroglia surround and segregate these cells in vivo or in vitro is dependent on STAT3 signaling within the astrocytes. It is noteworthy that the STAT3 signaling pathway mediates the effects of various cytokines and growth factors, including interleukin 6, ciliary neurotrophic factor, and LIF, which are released by various cell types at sites of CNS injuries and play roles in regulating inflammatory responses of various kinds (Hirano et al., 2000; Aaronson and Horvath,
2002). Last, we present evidence that there is a negative correlation between the presence of inflammatory cells and viable neurons, and a positive correlation between sufficient scar formation and viable neurons. Together, these findings strongly suggest that an important adaptive function of scar-forming astroglia is neuroprotective by corralling inflammatory cells in areas of severely damaged tissue and preventing the spread of these cells into neighboring neural tissue that contains viable neurons.

\section{References}

Aaronson DS, Horvath CM (2002) A road map for those who don't know JAK-STAT. Science 296:1653-1655. CrossRef Medline

Aldrich A, Kielian T (2011) Central nervous system fibrosis is associated with fibrocyte-like infiltrates. Am J Pathol 179:2952-2962. CrossRef Medline

Amat JA, Ishiguro H, Nakamura K, Norton WT (1996) Phenotypic diversity and kinetics of proliferating microglia and astrocytes following cortical stab wounds. Glia 16:368-382. CrossRef Medline

Bannerman P, Hahn A, Soulika A, Gallo V, Pleasure D (2007) Astrogliosis in EAE spinal cord: derivation from radial glia, and relationships to oligodendroglia. Glia 55:57-64. CrossRef Medline

Bardehle S, Krüger M, Buggenthin F, Schwausch J, Ninkovic J, Clevers H, Snippert HJ, Theis FJ, Meyer-Luehmann M, Bechmann I, Dimou L, Götz M (2013) Live imaging of astrocyte responses to acute injury reveals selective juxtavascular proliferation. Nat Neurosci 16:580-586. CrossRef Medline

Buffo A, Rite I, Tripathi P, Lepier A, Colak D, Horn AP, Mori T, Götz M (2008) Origin and progeny of reactive gliosis: a source of multipotent cells in the injured brain. Proc Natl Acad Sci U S A 105:3581-3586. CrossRef Medline

Bush TG, Savidge TC, Freeman TC, Cox HJ, Campbell EA, Mucke L, Johnson MH, Sofroniew MV (1998) Fulminant jejuno-ileitis following ablation of enteric glia in adult transgenic mice. Cell 93:189-201. CrossRef Medline

Bush TG, Puvanachandra N, Horner CH, Polito A, Ostenfeld T, Svendsen CN, Mucke L, Johnson MH, Sofroniew MV (1999) Leukocyte infiltration, neuronal degeneration and neurite outgrowth after ablation of scarforming, reactive astrocytes in adult transgenic mice. Neuron 23:297-308. CrossRef Medline

Bushong EA, Martone ME, Jones YZ, Ellisman MH (2002) Protoplasmic astrocytes in CAl atratum radiatum occupy separate anatomical domains. J Neurosci 22:183-192. Medline

Cahoy JD, Emery B, Kaushal A, Foo LC, Zamanian JL, Christopherson KS, Xing Y, Lubischer JL, Krieg PA, Krupenko SA, Thompson WJ, Barres BA (2008) A transcriptome database for astrocytes, neurons, and oligodendrocytes: a new resource for understanding brain development and function. J Neurosci 28:264-278. CrossRef Medline

Capela A, Temple S (2002) LeX/ssea-1 is expressed by adult mouse CNS stem cells, identifying them as nonependymal. Neuron 35:865-875. CrossRef Medline

Faulkner JR, Herrmann JE, Woo MJ, Tansey KE, Doan NB, Sofroniew MV (2004) Reactive astrocytes protect tissue and preserve function after spinal cord injury. J Neurosci 24:2143-2155. CrossRef Medline

Fawcett JW, Asher RA (1999) The glial scar and central nervous system repair. Brain Res Bull 49:377-391. CrossRef Medline

Foo LC, Allen NJ, Bushong EA, Ventura PB, Chung WS, Zhou L, Cahoy JD, Daneman R, Zong H, Ellisman MH, Barres BA (2011) Development of a method for the purification and culture of rodent astrocytes. Neuron 71:799-811. CrossRef Medline

Frisén J, Johansson CB, Török C, Risling M, Lendahl U (1995) Rapid, widespread, and long lasting induction of nestin contributes to the generation of glial scar tissue after CNS injury. J Cell Biol 131:453-464. CrossRef Medline

Gadea A, Schinelli S, Gallo V (2008) Endothelin-1 regulates astrocyte proliferation and reactive gliosis via a JNK/c-Jun signaling pathway. J Neurosci 28:2394-2408. CrossRef Medline

Garcia AD, Doan NB, Imura T, Bush TG, Sofroniew MV (2004) GFAPexpressing progenitors are the principle source of constitutive neurogenesis in adult mouse forebrain. Nat Neurosci 7:1233-1241. CrossRef Medline

Gerdes J, Lemke H, Baisch H, Wacker HH, Schwab U, Stein H (1984) Cell 
cycle analysis of a cell proliferation-associated human nuclear antigen defined by the monoclonal antibody Ki-67. J Immunol 133:1710-1715. Medline

Hamby ME, Coppola G, Ao Y, Geschwind DH, Khakh BS, Sofroniew MV (2012) Inflammatory mediators alter the astrocyte transcriptome and calcium signaling elicited by multiple G-protein-coupled receptors. J Neurosci 32:14489-14510. CrossRef Medline

Haroon F, Drögemuller K, Händel U, Brunn A, Reinhold D, Nishanth G, Mueller W, Trautwein C, Ernst M, Deckert M, Schlüter D (2011) Gp130-dependent astrocytic survival is critical for the control of autoimmune central nervous system inflammation. J Immunol 186:6521-6531. CrossRef Medline

Hatten ME, Liem RK, Shelanski ML, Mason CA (1991) Astroglia in CNS injury. Glia 4:233-243. CrossRef Medline

Herrmann JE, Imura T, Song B, Qi J, Ao Y, Nguyen TK, Korsak RA, Takeda K, Akira S, Sofroniew MV (2008) STAT3 is a critical regulator of astrogliosis and scar formation after spinal cord injury. J Neurosci 28:7231-7243. CrossRef Medline

Hippenmeyer S, Youn YH, Moon HM, Miyamichi K, Zong H, WynshawBoris A, Luo L (2010) Genetic mosaic dissection of Lis1 and Ndel1 in neuronal migration. Neuron 68:695-709. CrossRef Medline

Hirano T, Ishihara K, Hibi M (2000) Roles of STAT3 in mediating the cell growth, differentiation and survival signals relayed through the IL- 6 family of cytokine receptors. Oncogene 19:2548-2556. CrossRef Medline

Imura T, Nakano I, Kornblum HI, Sofroniew MV (2006) Phenotypic and functional heterogeneity of GFAP-expressing cells in vitro: differential expression of LeX/CD15 by GFAP-expressing multipotent neural stem cells and non-neurogenic astrocytes. Glia 53:277-293. CrossRef Medline

Jessell TM (2000) Neuronal specification in the spinal cord: inductive signals and transcriptional codes. Nat Rev Genet 1:20-29. CrossRef Medline

Kawano H, Kimura-Kuroda J, Komuta Y, Yoshioka N, Li HP, Kawamura K, Li Y, Raisman G (2012) Role of the lesion scar in the response to damage and repair of the central nervous system. Cell Tissue Res 349:169-180. CrossRef Medline

Klapka N, Müller HW (2006) Collagen matrix in spinal cord injury. J Neurotrauma 23:422-435. CrossRef Medline

Komitova M, Eriksson PS (2004) Sox-2 is expressed by neural progenitors and astroglia in the adult rat brain. Neurosci Lett 369:24-27. CrossRef Medline

Li Y, Li D, Ibrahim A, Raisman G (2012) Repair involves all three surfaces of the glial cell. Prog Brain Res 201:199-218. CrossRef Medline

Myer DJ, Gurkoff GG, Lee SM, Hovda DA, Sofroniew MV (2006) Essential protective roles of reactive astrocytes in traumatic brain injury. Brain 129:2761-2772. CrossRef Medline

Niclou SP, Franssen EH, Ehlert EM, Taniguchi M, Verhaagen J (2003) Meningeal cell-derived semaphorin $3 \mathrm{~A}$ inhibits neurite outgrowth. Mol Cell Neurosci 24:902-912. CrossRef Medline

Norton WT, Aquino DA, Hozumi I, Chiu FC, Brosnan CF (1992) Quantitative aspects of reactive gliosis: a review. Neurochem Res 17:877-885. CrossRef Medline

Oberheim NA, Tian GF, Han X, Peng W, Takano T, Ransom B, Nedergaard M (2008) Loss of astrocytic domain organization in the epileptic brain. J Neurosci 28:3264-3276. CrossRef Medline

Papadopoulos MC, Verkman AS (2013) Aquaporin water channels in the nervous system. Nat Rev Neurosci 14:265-277. CrossRef Medline

Ramon y Cajal S (1928) Degeneration and regeneration of the nervous system. London: Oxford UP.

Reilkoff RA, Bucala R, Herzog EL (2011) Fibrocytes: emerging effector cells in chronic inflammation. Nat Rev Immunol 11:427-435. CrossRef Medline

Robel S, Berninger B, Götz M (2011) The stem cell potential of glia: lessons from reactive gliosis. Nat Rev Neurosci 12:88-104. CrossRef Medline

Sarafian TA, Montes C, Imura T, Qi J, Coppola G, Geschwind DH, Sofroniew MV (2010) Disruption of astrocyte STAT3 signaling decreases mitochondrial function and increases oxidative stress in vitro. PLoS One 5:e9532. CrossRef Medline

Schachtrup C, Ryu JK, Helmrick MJ, Vagena E, Galanakis DK, Degen JL, Margolis RU, Akassoglou K (2010) Fibrinogen triggers astrocyte scar formation by promoting the availability of active TGF-beta after vascular damage. J Neurosci 30:5843-5854. CrossRef Medline

Shigetomi E, Bushong EA, Haustein MD, Tong X, Jackson-Weaver O, Kracun
S, Xu J, Sofroniew MV, Ellisman MH, Khakh BS (2013) Imaging calcium microdomains within entire astrocyte territories and endfeet with GCaMPs expressed using adeno-associated viruses. J Gen Physiol 141: 633-647. CrossRef Medline

Shimada IS, LeComte MD, Granger JC, Quinlan NJ, Spees JL (2012) Selfrenewal and differentiation of reactive astrocyte-derived neural stem/progenitor cells isolated from the cortical peri-infarct area after stroke. J Neurosci 32:7926-7940. CrossRef Medline

Shu SY, Ju G, Fan LZ (1988) The glucose oxidase-DAB-nickel method in peroxidase histochemistry of the nervous system. Neurosci Lett 85: 169-171. CrossRef Medline

Silver J, Miller JH (2004) Regeneration beyond the glial scar. Nat Rev Neurosci 5:146-156. CrossRef Medline

Silver J, Edwards MA, Levitt P (1993) Immunocytochemical demonstration of early appearing astroglial structures that form boundaries and pathways along axon tracts in the fetal brain. J Comp Neurol 328:415-436. CrossRef Medline

Sofroniew MV (2005) Reactive astrocytes in neural repair and protection. Neuroscientist 11:400-407. CrossRef Medline

Sofroniew MV (2009) Molecular dissection of reactive astrogliosis and glial scar formation. Trends Neurosci 32:638-647. CrossRef Medline

Sofroniew MV, Vinters HV (2010) Astrocytes: biology and pathology. Acta Neuropathol 119:7-35. CrossRef Medline

Sroga JM, Jones TB, Kigerl KA, McGaughy VM, Popovich PG (2003) Rats and mice exhibit distinct inflammatory reactions after spinal cord injury. J Comp Neurol 462:223-240. CrossRef Medline

Takeda K, Kaisho T, Yoshida N, Takeda J, Kishimoto T, Akira S (1998) Stat3 activation is responsible for IL-6-dependent $\mathrm{T}$ cell proliferation through preventing apoptosis: generation and characterization of $\mathrm{T}$ cell-specific Stat3-deficient mice. J Immunol 161:4652-4660. Medline

Tsai HH, Li H, Fuentealba LC, Molofsky AV, Taveira-Marques R, Zhuang H, Tenney A, Murnen AT, Fancy SP, Merkle F, Kessaris N, Alvarez-Buylla A, Richardson WD, Rowitch DH (2012) Regional astrocyte allocation regulates CNS synaptogenesis and repair. Science 337:358-362. CrossRef Medline

Voskuhl RR, Peterson RS, Song B, Ao Y, Morales LB, Tiwari-Woodruff S, Sofroniew MV (2009) Reactive astrocytes form scar-like perivascular barriers to leukocytes during adaptive immune inflammation of the CNS. J Neurosci 29:11511-11522. CrossRef Medline

Walker TL, Wierick A, Sykes AM, Waldau B, Corbeil D, Carmeliet P, Kempermann G (2013) Prominin-1 allows prospective isolation of neural stem cells from the adult murine hippocampus. J Neurosci 33:3010-3024. CrossRef Medline

Wanner IB (2012) An in vitro trauma model to study rodent and human astrocyte reactivity. Methods Mol Biol 814:189-219. CrossRef Medline

Wanner IB, Wood PM (2002) N-cadherin mediates axon-aligned process growth and cell-cell interaction in rat Schwann cells. J Neurosci 22:40664079. Medline

Wanner IB, Guerra NK, Mahoney J, Kumar A, Wood PM, Mirsky R, Jessen KR (2006) Role of N-cadherin in Schwann cell precursors of growing nerves. Glia 54:439-459. CrossRef Medline

Wanner IB, Deik A, Torres M, Rosendahl A, Neary JT, Lemmon VP, Bixby JL (2008) A new in vitro model of the glial scar inhibits axon growth. Glia 56:1691-1709. CrossRef Medline

White RE, McTigue DM, Jakeman LB (2010) Regional heterogeneity in astrocyte responses following contusive spinal cord injury in mice. J Comp Neurol 518:1370-1390. Medline

Wilhelmsson U, Bushong EA, Price DL, Smarr BL, Phung V, Terada M, Ellisman MH, Pekny M (2006) Redefining the concept of reactive astrocytes as cells that remain within their unique domains upon reaction to injury. Proc Natl Acad Sci U S A 103:17513-17518. CrossRef Medline

Zai LJ, Wrathall JR (2005) Cell proliferation and replacement following contusive spinal cord injury. Glia 50:247-257. CrossRef Medline

Zamanian JL, Xu L, Foo LC, Nouri N, Zhou L, Giffard RG, Barres BA (2012) Genomic analysis of reactive astrogliosis. J Neurosci 32:6391-6410. CrossRef Medline

Zhang Y, Barres BA (2010) Astrocyte heterogeneity: an underappreciated topic in neurobiology. Curr Opin Neurobiol 20:588-594. CrossRef Medline

Zong H, Espinosa JS, Su HH, Muzumdar MD, Luo L (2005) Mosaic analysis with double markers in mice. Cell 121:479-492. CrossRef Medline 